\title{
Risk management in international supply chains: the case of natural hedging
}

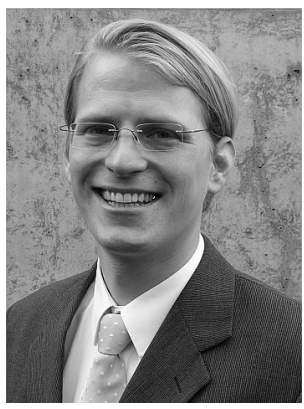

\section{Erik Hofmann}

Supply Chain Management, Finanzielles Hedging, Physisches Hedging, Value-at-Risk, Währungsrisiken, Rohstoffpreisrisiken, Gegengeschäft

Supply chain management, financial hedging, physical hedging, value-at-risk, currency risk, commodity price risk, countertrade

Das Management globaler Supply Chains bietet zahlreiche Wettbewerbschancen für Unternehmen. Allerdings sind die damit verbundenen Vorteile häufig eng mit Unsicherheiten und Risiken verbunden, wie z. B. die Volatilität von Wechselkursen oder Lieferengpässen auf Rohstoffmärkten. Diese Supply Chain-Risiken stellen besonders für kleine und mittelständische (KMU) Zulieferer ein signifikantes Risiko dar, welche durch Ein- und Verkaufsaktivitäten in unterschiedlichen Währungszonen zunehmenden Schwankungen ausgesetzt sind. Auf den Rohstoff- und Devisemärkten existieren zahlreiche Instrumente zur Absicherung von Risiken, die jedoch primär an der monetären Komponente ansetzen. Diese Ansätze adressieren überwiegend die Absicherung einer einzigen Problemstellung, während Natural Hedging innerhalb eines internationalen Supply Chain-Ausschnittes hingegen einen umfassenderen Risikopool mehrere Akteure zum Gegenstand hat. Innerhalb dieses interdisziplinären Konzepts „,hedged“ ein global aktives Grossunternehmen, z. B. ein finanzstarker Hersteller (OEM), sowohl finanzielle Wechselkurs- und Rohstoffpreisrisiken („Financial Options“), wie auch operationelle Risiken („Physical Options“) durch die Bündelung der Rohstofflieferungen seiner relativ finanzschwachen KMU-Zulieferer. Denn angesichts der Entwicklung auf den Weltmärkten ist die Fähigkeit, verschiedene Risiken mehrerer interagierender Akteure kooperativ integriert abzusichern, eine Stärke des Natural Hedging in internationalen Supply Chains. Dabei wird es den Idealen eines umfassenden und proaktiven Risikomanagements auf der Netzwerkebene gerecht. Natural Hedging kann zur Reduktion der Anfälligkeit von Zuliefer-Abnehmer-Beziehungen beitragen und somit zur Stabilisierung der gesamten Supply Chain führen. Die Vor-/Nachteile des Ansatzes werden mithilfe eines formalen, analytischen Models und einer SzenarioAnalyse dargestellt.

The management of global supply chains is a source of competitive advantage. The related benefits are, however, tightly coupled with rising uncertainty and risks such as the volatility of foreign exchange and commodity markets. These supply chain risks significantly endanger small and medium-sized (SME) suppliers that operate in different currency areas in purchasing and sales. Although significant advancements in the area of supply chain risk management have been achieved in the past, a brief look at the current literature shows that contributions often remain at a general and theoretical level. The present paper con- 
tributes a specific risk management approach for international supply chains, namely natural hedging. Within that interdisciplinary concept, a globally active focal firm - an original equipment manufacturer, for instance - hedges currency and commodity price risks (financial options) as well as operational supply risks (physical options) by centralizing commodity supply with its SME suppliers. Natural hedging can contribute to the reduction of SME suppliers' supply chain vulnerability in the interests of the entire supply chain. The findings are explained within a formal analytical model and a scenario analysis.

\section{Introduction}

The global economy is currently characterized by an increasing international division of labor, by the formation of worldwide value networks and by the development of new markets for sales and purchasing. The international interdependence of these value adding processes not only provide opportunities for companies but also suggest several threats, which arise, for instance, from volatile and mostly rising prices for commodities as well as from fluctuating exchange rates. Companies that import their input goods or export their products from or into foreign currency areas within the context of low-cost-sourcing are mainly affected by these kinds of risks. With regards to the financial situation and the underlying supply chain configuration, the risk of fluctuating commodity prices and exchange rates can have different effects on companies.

Until the first half of 2008, commodity prices rose dramatically (Teague 2009). This increase in prices was caused by different factors. Unlike the stock market, commodity trade merely underlies political incidents and environmental influences than speculative trends. Hence, price developments are reflected in the political developments in those countries with high amounts of commodities. In addition to commodity prices, currency fluctuations also must be accounted for (Sedgwick et al. 2008). The Euro gained stability up to 2007, while the US dollar dropped to an all-time low versus the young currency. These kinds of developments in the currency market generate possible risks for companies that pursue business activities in different currency areas (Cohen 2009). In particular, periods of high volatility as experienced in 2008 and the first quarter of 2009 can harm small and medium-sized enterprises (SME). However, in the context of long-term large-volume orders, even small changes can have a devastating, negative impact.

The risks for SME suppliers that arise from purchasing their commodities, input goods and services or selling their products in international markets tend to be higher than are those for larger and financially stronger corporations. Often SME suppliers do not dispose of financial possibilities or sufficient human resources to hedge strongly fluctuating commodity prices and exchange rates. Because these companies are usually in supplier-customer relationships with large corporations (e.g. an original equipment manufacturer, OEM, in the automobile industry), the risk could ultimately strike through to the latter (Cossin/Schellhorn 2007). Thus, this turns into a supply chain risk induced by commodity and currency fluctuations. In particular, if fluctuating prices or exchange rates harm the SME to an extent that its existence becomes endangered, significant consequences for the entire supply chain (network) can occur. Hence, supply availability is affected, which can lead to financial losses for the OEM due to lost output, halted production lines or image losses. Therefore, large corporations also have an interest in helping reduce the currency and commodity price risks for their SME suppliers (Norrman/Jansson 2004). The situation calls for an integrated risk management approach to international supply chains on 
the basis of hedging. This is where the concept of natural hedging makes a significant contribution to the supply chain members. The concept aims at reducing supply chain vulnerability by hedging an SME supplier's risks in connection with commodity supply from an OEM's perspective.

The current literature has caught up on supply chain risk management research in the past decade (e.g. Barry 2004; Cavinato 2004; Chopra/Sodhi 2004; Christopher/Lee 2004; Kleindorfer/Saad 2005; Tang 2006). Much empirical research has been performed in the area of risk sources and their effects on supply chains as well as overall economic performance (e.g. Hendrick/Singhal 2005). Authors have also started generating risk management strategies by partially applying general risk management conceptions (e.g. Das/Teng 1998). However, little has been done to assess international risk management strategies such as hedging, especially concerning supply chains containing SME suppliers with a high financial vulnerability (Zsidisin et al. 2004). There seems to be agreement that the risks and consequences of supply chain disruptions are growing and that they cannot be understood and managed solely at the single company level (Manuj/Mentzer 2008 a). There is a need to clearly address the possibilities of large focal firms taking over a leading role in a supply chain (network) by adopting the risks of its SME suppliers. Hence, such a proactive cooperation, especially concerning both financial and physical risks in supply chains within a hedging approach, calls for a deeper examination. Therefore, the current paper's research question is:

'How can financial and physical hedging reduce the supply chain vulnerability of SME suppliers in an international context and what potential does it have from a focal buying firm's perspective?'

The methodology applied to answer this real world risk-taking question is based on 'conceptual' theory building according to Meredith (1993) and Wacker (2008). This paper is based on conceptual thoughts transformed into an analytical model derived from current literature on hedging and supply chain risk management. The interdisciplinary paper is meant to describe the dynamics of natural hedging formally in order to perform scenario analysis. The concept distinguishes the financial and physical options of natural hedging. This distinction will be followed throughout the model. The financial options according to financial market risks will be built on the value-at-risk method (Jorion 2002), while the physical options will concentrate on comparing changes in efficiencies as a result of the implementation of natural hedging. The focus within the model lies on the potential of the supply chain risk approach rather than specific costs or profits. A scenario analysis is conducted by defining specific variables. The model therewith illustrates the dynamics of natural hedging on the one hand. On the other hand, insights are obtained into the change in potential upside or downside of the approach. Finally, statements on possible adoptions within the concept will be made by analyzing the central drivers of natural hedging by both maximizing the upside and minimizing the downside potential.

The present paper is organized as follows. Section 2 starts with the theoretical background on the main topics surrounding the research question. It will present the context of supply chain risk management by introducing and explaining the concept of natural hedging. In Section 3, a formal model of natural hedging is developed. Section 4 will introduce a scenario analysis before concluding the paper with the final words and an outlook for further research in Section 5. 


\section{Theoretical background}

\subsection{Managing risk in international supply chains}

A goal of supply chain management is to maximize profits and thus to find a balance between productivity and profitability as a whole in order to move goods at the required quality at a specific time, mostly into a different country (Mentzer et al. 2001). Hence, the potential for possible uncertainties has risen with the globalization of supply chains (Manuj/Mentzer 2008 a). Since the globalization of markets and thereby supply chains bring many advantages (such as the transnational mobility of capital, information, people, products and services, or the ability to exploit economies of location), a company will seek to handle the challenges rather than renouncing the potential of internationalization (Cohen/Mallik 1997; Barry 2004). For the purpose of this paper, these challenges are similarly seen as a sum of specific risks.

Supply chain risk in general can be defined as disruption or damage, as evaluated by its occurrence probability, that affects more than just one company and that occurs within a company, the supply chain or its environment (Harland et al. 2003). Hence, risks in the supply chain may arise from the unintended change of 'flows' between organizations. These flows relate to materials (or products), information and money (Tang 2006). In particular, in international supply chains, the time until the goods reach their final destinations and the way how payments are settled can be harmed. Additionally, the spectrum of imponderable events is wider and more diverse in the international context (e.g. sudden price fluctuations). There are more risks attached to trading internationally because consignments must cross national borders as well as authorization zones. Risks in international supply chains can be found on the side of the importing and exporting companies during the transfer of goods and money. Globally active companies are often both an importer on the supply side and an exporter on the demand side.

Apart from conflicting interests between the importer and exporter, there are also risks that cannot be influenced by any party in an international supply chain (Jacques 1981; Watson 1994):

- Business risks: This risk category is characterized by the inability or refusal of the foreign partner to deliver (supplier) or to pay (customer). This may occur in various cases, for example, if the business partner declares bankruptcy, is a beguiler, changes his or her mind or claims a fault.

- Transit risks: Goods travel much further in international supply chains than they do in a domestic deal, and therefore there is more danger of loss or damage to the goods on their journey from the supplier to its customers.

- Currency risks: These are part of political risks and arise because of the sovereignty of countries. Governments may use alternative methods to control imports by setting up restrictions such as tariffs or non-tariff barriers including import quotas, currency restrictions or the pure prohibition of illegal or harmful items. Among others, the political risk can be sub-divided into conversion and transfer risk, exchange rate risk and interest rate risk.

To overcome the risk of international trade and to reduce the vulnerability of their crossborder activities, companies must have more knowledge about its drivers and enhance supply chain resilience to allow 'the ability of a system to return to its original (or desired) state after being disturbed' (Peck 2005). In general, risk in supply chains is managed ac- 
cording to the risk management process in a single company (White 1995; Simons 1999). Cucchiella and Gastaldi (2006), for instance, developed a six-step process for supply chain risk management (see also Harland et al. 2003). Manuj and Mentzer (2008 b) aligned their supply chain risk management process along the general risk management process by identifying and evaluating risks, selecting appropriate management strategies and implementing the strategies to finally mitigate the risk. These authors presented seven categories of risk management strategies: avoidance, postponement, speculation, control, sharing, transferring, security and hedging (see accordingly Jüttner et al. 2003).

In particular, hedging is defined as an intentional limitation of threats through a compensation of risks in international trade (Kyte 2002; Caldentey/Haugh 2006). The referred risks arise from real business transactions such as purchasing commodities and selling finished goods in different currency areas and from different solvency partners and shipping different distances (Allayannis et al. 2001). On the one hand, they express the capital value insecurity of all future revenues converted into domestic currency depending on the exchange rate realization. On the other hand, this risk aims at threats arising with the (geographically) allocation of production factors, mainly meaning risks in the fulfillment of demand and supply risks (Ding et al. 2007). Hence, the definition of hedging has a financial and operational compensatory effect, which is implemented through the balance between potential wins and losses (Takezawa et al. 2007). An activity that is fraught with risk is hedged through a countertrade that has a contrasting risk, although a certain risk still remains. To reduce the latter, further hedging activities can be made. However, a loss of possible profits must be taken into consideration because of these opposed deals. Hence, the main goal of hedging is to reduce risks and not to realize speculative wins (Guay/ Kothari 2003).

Hedging in international supply chains consists of the joint use of financial and operational options and encompasses at least two interconnected companies, which source or sell in different countries in the presence of demand and exchange rate (price) uncertainties (Ding et al. 2007). Recent literature such as Vaagen and Wallace (2008), Caldentey and Haugh (2009) or Kuwornu et al. (2009) has suggested that in cases of high risk on the supplier side (e.g. SME suppliers who cannot hedge their own financial risks), focal firms - such as an OEM - can take over certain risks collaboratively by bundling them and in this way secure the existence of its own suppliers. The focus therewith lies in hedging currency and commodity price fluctuations.

International corporations such as large automobile producers, for instance, have recognized the possibility to partially hedge potential currency risks with their own foreign currency assets (Duangploy/Helmi 2000). The hedge volume of the VW group, for instance, amounted up to approximately USD 6 billion in 2003, which was half of VW's export volumes in US dollars during that time (VW Investor Relations 2004).

\subsection{The concept of natural hedging in international supply chains}

Supply chains are often characterized by an international dispersed portfolio of suppliers, customers and facilities so that a single event such as currency fluctuations does not affect all units at the same time or with the same impact (Manuj/Mentzer $2008 \mathrm{~b}$ ). Basically, the underlying asset of a hedging activity can assume any shape. Objects that have a quoted price base such as commodities or derivatives are common (Schrand/Unal 1998; Ding et al. 2007). Natural hedging should be regarded as an instrument of real economical risk 
management where transactions are hedged through real economic counter deals (Makar et al. 1999). Therefore, the term 'natural' describes the real economy; in other words, the physical part of the concept. Unlike pure financial instruments, natural hedging secures not only the price but also the quantity or the readiness for delivery. It also has significant influence on purchasing or production decisions. In a more narrow interpretation of the term, derivatives are not contracted in the financial market as they are in traditional hedging approaches. From a broader perspective, quoted products such as commodity certificates can also be integrated if they are available. Hence, natural hedging is attractive for companies if they are active in different countries and are subjected to a massive demand of commodities as well as to currency fluctuations.

Natural hedging in international supply chains aims at an intentional and target-oriented exercise of influence on risks of two or more companies in a cross-border value network, whereas one company takes threat limiting actions in favour of another partner. Therefore, natural hedging in supply chains enhances existing hedging approaches by including the partners of a value network (Takezawa et al. 2007). Receivables from the overturn of a supplier and the liabilities from the purchase of a customer are aligned with the corresponding flow of goods or cash. Hence, negatively correlating risks within a specific supply chain section can be merged and aligned regarding monetary amounts and deadlines. Therefore, instead of hedging single positions the difference coming from all interactions of the supply chain actors can be hedged jointly. Thus, the 'real economic' hedging of currency and commodity price risks takes place within the supply chain section because of actively influencing the flow of goods and cash. Hedging the overall risk of a supply chain section is done by means of classical instruments of financial hedging (e.g. currency or commodity certificates).

In addition to financing the supplier, the natural hedging approach additionally secures the availability of commodities for the involved companies. Forward contracts with defined durations can further limit the maximal price increase for commodities through call options (Schrand/Unal 1998). At the same time, these kinds of activities cause coordination and transaction costs between supply chain actors. The implementation of natural hedging must be evaluated on the basis of a cost-benefit or up-and-downside analysis. Overall, a 'critical' amount can be determined through the bundling of purchasing volumes at which a certain hedging approach pays off.

The automobile industry, for instance, has already implemented this method (Devlin 2004). Producers relocate parts of their productions to foreign currency areas. Therefore, the demand for foreign currencies is balanced out up to a certain extent within the affiliated group and this can act to divert risk for suppliers (Snyder/Ostle 2003). The effective, physical relocation to hedge the underlying asset can be problematic. With rising prices for commodities and consumables, the advantage of purchasing input goods in the respective currency areas is limited. Additionally, natural hedging implies an intentional transfer of risk. Price development cannot be hedged in the long run and must be taken into consideration by the supplier and the customer within the planning phase. As with 'classical' hedging, natural hedging also cannot secure $100 \%$ of the risk. The approach should rather contribute to securing short-term volatility within a supply chain. 


\subsection{Characteristics of natural hedging in international supply chains}

The main characteristics of natural hedging will be exemplified using a fictitious example. The business relation between an SME supplier (Tier 1) and a large manufacturer (OEM) is the initial point of observation as this can mostly be found in the automobile industry. Both companies operate in currency area A. The SME supplier exclusively produces specialized parts for automobile manufacturers. Therefore, commodities or semi-finished goods are purchased at a further commodity supplier (Tier 2), which is located in currency area B. Further, it is assumed that the OEM depends on the semi-finished goods of the supplier and that no competitors or substitution products are available in the short run. By contrast, the supplier depends on the OEM as its main customer. Further, it can be assumed that the Tier-1 supplier does not have large financial reserves and that the purchase of materials forms the largest part of its financial resources.

Owing to possible commodity price and exchange rate fluctuations, the following risks can occur for the SME supplier:

- Owing to the relatively small purchase quantities involved, a potential risk of unavailability exists for the SME supplier. This can mainly be expected if the Tier 2 commodity supplier has capacity constraints and thereby prefers to supply larger customers.

- Continuous fluctuations in derivative markets and exclusive activities in currency area $\mathrm{B}$ on the purchasing side and currency area A on the sales side lead to a currency risk for the SME supplier. The cost-intensive development of currency management or the billable usage of hedging instruments prevents an economic reduction of currency risks.

- Owing to volatile commodity prices on the world market, a price risk in terms of the required raw materials exists for the SME supplier. An adequate hedge of single components with 'classical' financial derivatives is mostly impeded because of limited management capacities and missing know-how. In addition, the respective fees for listed hedges hamper an economic execution of future or option contracts.

Apart from the Tier 1 supplier, the OEM is also exposed to risks in this situation:

- The accumulated risks of the SME supplier could lead to the non-availability of input goods for the OEM because of supply bottlenecks or even insolvency. For instance, this might cause costs due to idleness, damage to the company's image or supplementary grants because of damage limitation activities.

- As the supplier, the OEM is also exposed to many commodity price and currency risks. However, it has larger resources to deal with single risk sources within the scope of supply chain risk management.

The flows of goods and materials by the involved supply chain actors without a natural hedging approach are illustrated in Figure 1. For the initial situation, the following can be concluded. Because of the strained financial situation of the SME supplier, a latent supply chain risk exists for the OEM. Therefore, in the contractually defined supplier-customer relationship the SME supplier cannot entirely pass down price increases that arise from commodity price changes or currency fluctuations. These price risks can lead to lost profit and thereby insolvency. The possibility to integrate an indexation clause in the supply contract between the Tier 1 supplier and the OEM concerning commodity price and currency fluctuations does exist (Plambeck/Taylor 2007). However, an 'intentional' hedge from a superior network view can thereby not be achieved. Only the financial risks of the SME supplier can be addressed. The implementation of a comprehensive natural hedging approach with its financial and physical elements seems to show more promise. 

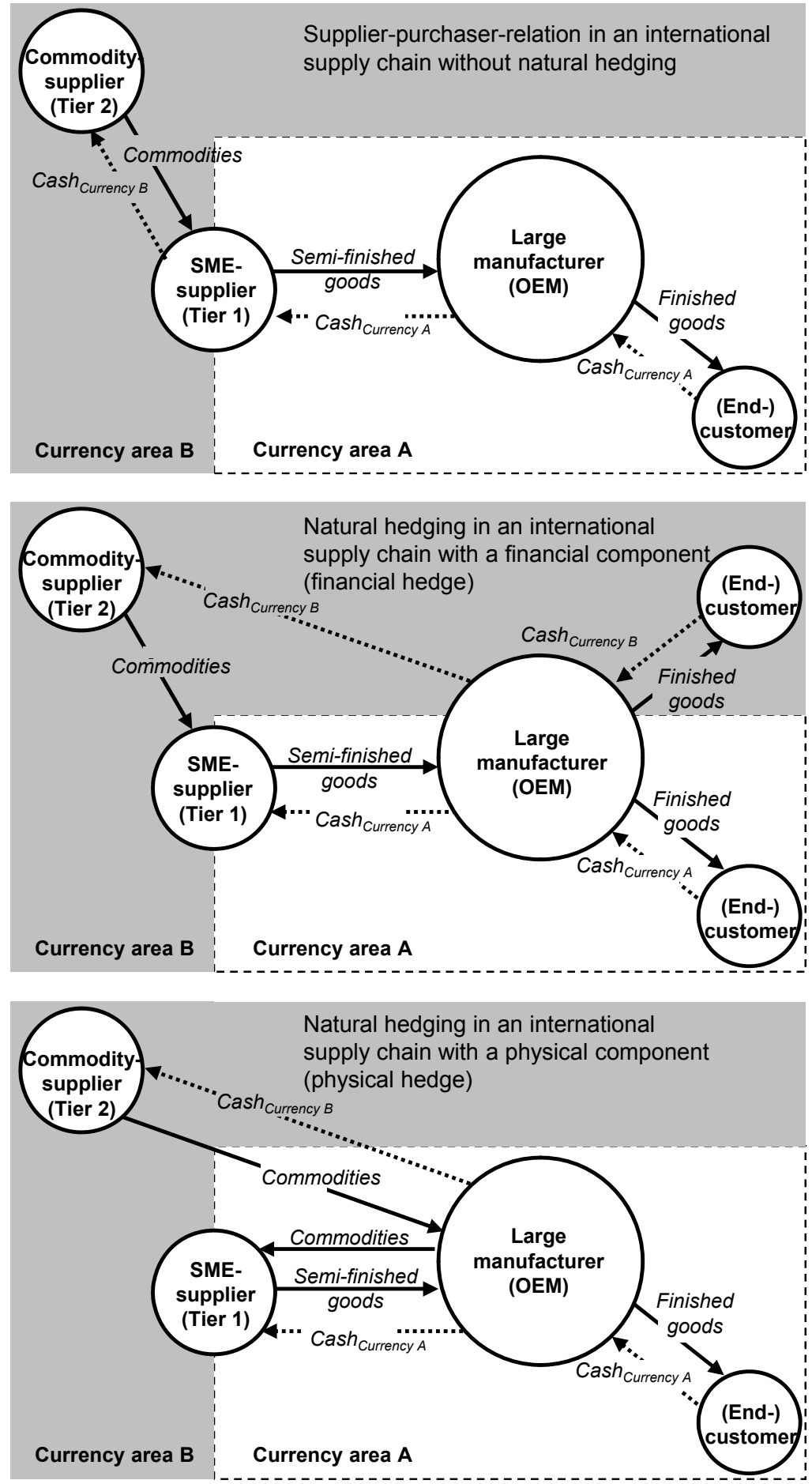

Figure 1: Illustration of initial situation and natural hedging alternatives in international supply chains 


\section{Financial hedge in international supply chains}

In a further consideration, the OEM is also active in currency area B while selling its finished goods to end customers in that market. Hence, it acquires currency B and can pay the commodity supplier (Tier 2) of its supplier (Tier 1) directly. The OEM can thereby support the SME supplier by taking over the currency risk. The idea of natural hedging in supply chains is justified. Since this alternative 'merely' affects the flows of goods, it is termed the 'financial element of natural hedging in supply chains' or 'financial hedge' for short. The OEM has the possibility to bundle negatively correlating risks as well as to align them according to their due dates (e.g. cash pooling).

\section{Physical hedge in international supply chains}

In addition to the financial hedge, a physically oriented version is possible. Assume that the OEM is no longer active in currency area B. Nonetheless, it takes over the currency risk and pays the Tier 2 commodity supplier directly in the respective currency. In addition, the flow of materials is 'reorganized' and is not carried out through the Tier 1 supplier but initially through the OEM. This alternative corresponds to a 'vertical purchasing cooperation' or a centralized purchasing approach at the network level (Tella/Virolainen 2005). Owing to the modified flows of materials, it is termed the 'physical element of natural hedging in supply chains' or 'physical hedge' for short. In this version, the OEM solely carries the supply risk for the purchased commodities.

Concerning the cooperation between SME suppliers and the OEM different kinds of characteristics can also be identified within a physical hedge in supply chains. Provided that the OEM requires the same commodities as does its SME supplier, the OEM can achieve better purchasing conditions by bundling larger amounts of commodities. The SME supplier's demand is included in the purchasing activities of the OEM or is directly carried out in Tier 1 . In case of a supply bottleneck, a second alternative could be for the large manufacturer to provide the Tier 1 supplier with materials from its own stock in the short-term. In addition to securing the quantity, delivery time risk can also be reduced. This, the premise is that the OEM requires the same commodities and materials as does the Tier 1 supplier.

\section{Combination of financial and physical hedge in international supply chains}

Finally, a combination of the financial and physical hedge is possible. Such a constellation implies higher coordination and cooperation efforts. The integrated approach is especially appropriate when a supplier has a dominant role (e.g. innovation leader) but at the same time does not dispose of enough financial resources. Such physical and financial hedging can nowadays be found in a few practical examples such as in the value network of Siemens (Vermond 2007). Overall, the risk management costs in a supply chain section can be reduced through the natural hedging approach at the network level since the costs to hedge single risks are higher for one actor than the costs for the harmonized hedging of bundled risks.

The following example outlines the main aspects of natural hedging. With the implementation of natural hedging within an observed international supply chain section, some sort of financing of SME suppliers can be ensured. By contrast, the collaborative hedging of purchasing risks for the involved supply chain members is provided. The Tier 1 supplier 
is thereby liberated of currency risks through the natural hedging approach. The subsequent combined reduction of insolvency risk for the SME supplier constitutes a first component of the approach from the OEM's point of view. This concept allows the OEM to internalize the financial risks and control the allocation of commodities. Overall, this seems to have positive effects since it aims at reducing SME supplier vulnerability and thereby supply chain risk. However, the concept is theoretical and must be analysed in depth. The potential benefits of natural hedging were made clear. Moreover, a reorganization of the international supply chain as suggested above does not evolve without additional costs. The strengths of the approach lie in a risk reduction, although implementation costs must be taken into account. Hence, the application of natural hedging must be confined to precious and long-term relationships in the supply chain.

The following section provides a model that will assess the potential of natural hedging in international supply chains by identifying and differentiating all potential upside and downside elements.

\section{The model}

\subsection{Principles of the natural hedging model}

This model will be based on a defined framework and the specific assumptions made in connection with the general concept of natural hedging. The starting point is a simplified international supply chain as depicted in Figure 1. To keep the model simple and explicable, the framework is constrained to two currency areas, A and B (e.g. US dollar and Euro). Further, it is assumed that the OEM has high barrier costs to change its Tier 1 supplier for the semi-finished good. Thus, the relationship between the SME supplier and the OEM has a long-term character. The model also clarifies that the SME supplier solely produces its goods for the OEM manufacturer. All formulas and calculations are based on a one-year period. Finally, the SME suppliers are assumed to be located close to the OEM as seen in many industrial supply chains (e.g. the automotive industry). The commodity Tier 2 suppliers, however, are assumed to be located overseas.

As already explained, the concept of natural hedging in supply chains mainly comprises two elements: the financial part, in which the OEM hedges the SME supplier's currency risk as well as the commodity price risk through derivatives and similar hedging tools, which are already applied by the OEM for its own purposes, and the physical part, in which the OEM purchases the required commodities and takes over the SME supplier's supply risk. Both the financial and physical elements will be analyzed separately. In a first step, the focus lies on the financial option of natural hedging where the value-at-risk approach will be applied. Therefore, the potential upside and downside will be assessed. The second step will assess how the physical option affects the concept of natural hedging. Therefore, three main supply cost drivers will be analyzed. This will provide an overview to how the physical part of natural hedging works. The potential up- and downsides of the physical part will also be assessed by comparing supply costs before the implementation of natural hedging in the status quo (SQ) with the post-implementation situation with natural hedging $(\mathrm{NH})$.

The main goal of the model is to illustrate the drivers of natural hedging. The model is not meant to be a profit calculation on the basis of activity-based costing nor is it a net 
present value calculation. Therefore, at the highest aggregation level, the central formula will be:

$E_{\Pi}=\left[\Pi_{F H}^{+}-\Pi_{F H}^{-}\right]+\left[\Pi_{S C}^{S Q}-\Pi_{S C}^{N H}\right]$

with

$E_{\Pi}=$ Overall potential of natural hedging in international supply chains

$\Pi_{F H}^{+}=$Potential upside of financial options

$\Pi_{F H}^{-}=$Potential downside of financial options

$\Pi_{S C}^{S Q}=$ Potential supply costs $(\mathrm{SQ})$ without physical hedge elements

$\Pi_{S C}^{N H}=$ Potential supply costs $(\mathrm{NH})$ with physical hedge elements

\subsection{Financial hedge elements}

Financial hedge elements are implemented within the context of natural hedging to secure assets from market volatilities. Hence, the upside of the financial options of natural hedging is the value-at-risk $(\mathrm{VaR})$ to which the SME supplier and ultimately the OEM are exposed to (Jorion 2002; Sanders/Manfredo 2002; Choudhry 2006). In other words, by applying financial hedging the value-at-risk approach can be avoided.

Hedge accounting mainly focuses on managing different currencies within a company (Makar et al. 1999). The approach thereby concentrates on the purely monetary aspects of hedging. Hedge accounting is applied in practice by companies that are active in different currency areas (Adams/Montesi 1995). This simplifies accounting construction and counteracts currency volatilities (Caldentey/Haugh 2006). Hedge accounting itself, however, only has a limited effect on reducing risk within a supply chain since the method is based solely on the financial perspective of a single actor.

To evaluate the hedge accounting approach while extending the activities from a single company- to a supply chain-oriented view, the following formula is given:

$\Pi_{F H}^{+}-\Pi_{F H}^{-}=\left(V_{\text {Supply }}+\right.$ volume discount $)$

$$
\text { - (HR costs + hedging fees + risk of deterioration + steady residual risk) }
$$

There are two main drivers for the potential upside of the financial hedging:

- The internalization of the SME suppliers' financial value-at-risk through the OEM frees the suppliers from insolvency due to currency and commodity price fluctuations. Ultimately, the OEM can secure supplies of semi-finished goods to a certain extent.

- Assuming that the OEM already purchases the commodity being hedged, it has considerably higher purchasing power than does a SME supplier. In addition, since natural hedging can be applied to a supply chain network (with multiple suppliers demanding the same commodity), a larger purchasing volume, which is bundled by the OEM, can lead to a reduction in price per unit.

The potential downside of financial hedging comprises four main components:

- Depending on how extensive the OEM already hedges its own assets, the implementation of financial hedging within the scope of natural hedging will lead to higher costs in human resources. If the OEM only hedges a small amount of its own assets, the additional costs will be higher than if the OEM already has an extensive risk management 
team in place. This additional cost component is assumed to be small since the additional costs per unit are low.

- Each hedging activity (transaction) is linked to a hedging fee. The costs thereby depend on how many times transactions take place.

- By purchasing commodities for the SME suppliers, the OEM internalizes the risk of deterioration or credit risk until the commodities are sold. Therefore, the OEM risks that an SME supplier, for some reason, cannot pay the ordered commodities.

- Even though the OEM internalizes financial $V a R$, there remains a steady residual risk since a $100 \%$ hedge is difficult to achieve (Jorion 2002).

\section{Potential upside of the financial options}

Volatilities in the foreign exchange and commodities markets can have major destabilizing effects for SME suppliers mainly because of missing managerial and financial resources. The main reason is the assumption that SME suppliers are extensively exposed to exchange rate volatilities since they purchase in a different currency area to where they sell. Hence, an SME supplier cannot hedge its own risks. A sudden change in exchange rates or rises in commodity prices can ultimately lead to an SME's insolvency, and this financial risk can turn out to be critical for the entire supply chain (network) because of an interruption to the flow of goods. By taking over the mentioned financial market risks within the scope of natural hedging, the OEM can ultimately avoid the supply risks of semi-finished goods. The value of such a risk approach can thereby be applied.

The value-at-risk because of exchange rate volatilities for the SME supplier $\left(V_{a} R_{C}\right)$ will be derived on the basis of the variance/covariance (or analytical) method (Jorion 2002; Gotoh/Takano 2006). Therefore, the standard deviation $\sigma_{c}$ is needed. Once the required data are available, the $\mathrm{VaR}_{C}$ is calculated as follows:

$\operatorname{VaR}_{c}=\left(z_{\alpha} \cdot \sigma_{c} \cdot f_{X_{t}}\right)$

The formula states the highest possible loss at a historical volatility of $\sigma_{c}$, which is multiplied by the exchange rate at the time $t$ and scaled by the factor $z_{\alpha}$ (which describes the confidence interval of $\alpha$ ). Value-at-risk calculations in practice commonly use a confidence interval of $\alpha=95 \%$ or $99 \%$ (Denk/Exner-Merkelt 2005).

The calculation of commodity prices follows the similar procedure and prices are calculated with the same formula. In this case, the formula:

$\operatorname{VaR}_{c}=\left(z_{\alpha} \cdot \sigma_{p} \cdot V_{t}\right)$

is composed by the standard deviation (volatility) $\sigma_{p}$, the value of the commodity at the time $t\left(V_{t}\right)$ and $z_{\alpha}$.

Since the financial risk in this case is made up of two risk factors, an aggregation of the single value-at-risk values to a portfolio $V a R$ is necessary. However, a simple addition of the values would disregard the usual diversification effects. Hence, to account for the latter, the correlation coefficient $\left(k_{c, p}\right)$ must be applied. Therefore, the total financial $\operatorname{VaR}_{F}$ is calculated as follows: 


$$
\operatorname{VaR}_{F}=\sqrt{\operatorname{VaR}_{c}^{2}+\operatorname{VaR}_{p}^{2}+2 \cdot \operatorname{VaR}_{c} \cdot \operatorname{VaR} R_{p} \cdot k_{c, p}}
$$

\begin{tabular}{ll}
\hline \multicolumn{1}{c}{ Explanation } \\
\hline$V a R_{F}$ & $\begin{array}{l}\text { Potential, maximal financial loss of the portfolio composed of currency and com- } \\
\text { modity price VaR at confidence interval of } \alpha\end{array}$ \\
$V a R_{p}$ & $\begin{array}{l}\text { Potential, maximal financial loss for on commodity price purchase at a confidence } \\
\text { interval of } \alpha, \text { a volatility of } \sigma_{p}, \text { and a value of } V_{t}\end{array}$ \\
$V a R_{c}$ & $\begin{array}{l}\text { Potential, maximal financial loss on currency volatility a confidence interval of } \alpha, \text { a } \\
\text { volatility of } \sigma_{c}, \text { and a value of } f_{X_{t}}\end{array}$ \\
$z_{\alpha}$ & $\begin{array}{l}\text { Scaling factor at a confidence interval of } \alpha \text { and the assumption of a normal distri- } \\
\text { bution }\end{array}$ \\
$\sigma_{p}$ & Volatility of commodity price over period of analysis (one year) \\
$\sigma_{c}$ & Volatility of exchange rate over period of analysis (one year) \\
$k_{c, p}$ & Correlation factor between currency and commodity price \\
$f x_{t}$ & Initial commodity price \\
$V_{t}$ & Initial exchange rate \\
\hline
\end{tabular}

Table 1: Explanation of financial VaR

The potential upsides of financial hedging are given by:

$\Pi_{F H}^{+}=$prevented losses because of SME supplier insolvency + volume discount

The calculation in the previous paragraph expresses the value-at-risk that the SME supplier faces without hedging possibilities (Table 1). Hence, this also reflects the potential of natural hedging in the supply chain since the calculated risk not only affects the SME supplier but also the entire supply chain (network). However, this effect is indirect, and the $\operatorname{VaR}_{F}$ thereby cannot be used directly in the model since it primarily affects the SME supplier. The risk for the OEM is ultimately the supply risk, which can be caused by a possible insolvency of the SME supplier because of the volatilities in currency and commodity price markets.

The direct effect of the $\operatorname{VaR}_{F}$ expresses itself within the activities of the SME supplier. In other words, the risk depends on how sensitive the SME supplier is to the $\operatorname{VaR}_{F}$. The present model will simplify this sensibility by introducing a liquidity threshold as variable $F_{S}$, which represents the monetary limit at which the SME supplier can no longer cope with the volatilities. This context can thereby be described as:

If $\operatorname{VaR}_{F}>F_{S} \rightarrow$ Insolvency of the SME supplier $\rightarrow$ Outfall of supply to OEM.

The consequence of insolvency is the outfall of supply to the OEM. The latter can cope with this situation, as long as it has the purchased semi-finished products on stock. The amount of semi-finished goods that were supposed to be delivered to the OEM within the defined time frame of a year is $(Y)$. This amount is subject to an outfall due to insolvency. To calculate how the outfall affects the OEM in terms of profit an assumption on the 
amount of security storage $s$ of the semi-finished goods is required. The storage is calculated by multiplying $Y$ by a factor $\varphi$, which expresses the part kept in storage:

$s=Y \cdot \varphi$

If the OEM holds the amount $s$ in storage, the net loss of goods is expressed as:

$y_{I}=Y-s$

To derive the loss in terms of profit a further variable must be introduced that describes the profit made per unit of the purchased good $\left(p_{u}\right)$. Hence, the lost profit is:

$P_{l}=y_{l} \cdot p_{u}$

$P_{I}$ ultimately describes the $\operatorname{VaR}_{F}$ from the perspective of the OEM, resulting from the currency and commodity price risks.

A further benefit of financial hedging for the OEM follows the assumption that a $\mathrm{vol}$ ume discount is granted when purchasing large amounts from a Tier-2 commodity supplier. Hence, adding the volume of all the involved suppliers (provided they demand the same kind of commodity) to the existing demand of the OEM would reduce the price per unit (or weight). The upside for the OEM is ultimately expressed in a reduced price per unit for the semi-finished goods produced by the SME supplier. The calculation of the latter follows two steps.

Firstly, the relative price reduction must be calculated. Therefore, the formula for volume discount is applied with $m$ as the purchased amount and $P_{1}$ as original price per unit. The variables $w$ and $\mu$ describe the discount value curve:

$r_{O E M}=m^{W} \cdot \mu \cdot P_{1}$

Once the supply cost reduction for the specific commodity has been calculated, the second step focuses on the composition of the total costs per unit for the SME supplier. For instance, the total cost per unit can be made up of components such as commodity supply costs $(a=50 \%)$, production costs $(b=30 \%)$ and labor costs $(c=20 \%)$. Assuming that the margin for the SME supplier remains fixed, the cost reduction rate equals the reduction in price per unit. Hence, the total value saved by the volume discount is calculated as follows:

$V_{D}=P_{1}-\left(P_{1} \cdot r_{O E M} \cdot a\right)$

Note that $V_{D}$ represents a potential upside of physical hedging that arises from bundling commodity volumes from all the suppliers demanding the same commodity product (Table 2). 


\begin{tabular}{|c|c|}
\hline & Explanation \\
\hline$F_{S}$ & Represents $\operatorname{VaR}_{F}$ at which the SME-supplier can't cope with the financial loss due \\
\hline & Amount of semi-finished goods that the OEM holds on stock \\
\hline Y & $\begin{array}{l}\text { Amount of semi-finished goods which the SME-supplier is supposed to deliver but } \\
\text { cannot due to } \operatorname{VaR}_{F}>F_{S}\end{array}$ \\
\hline$\varphi$ & Factor which describes how much the OEM holds on stock \\
\hline$y_{1}$ & $\begin{array}{l}\text { Amount of semi-finished goods lost due to the SME-supplier's insolvency (minus } \\
\text { stock) }\end{array}$ \\
\hline$p_{u}$ & Profit the OEM makes per unit of semi-finished goods \\
\hline$P_{1}$ & Total profit loss due to SME-supplier's insolvency \\
\hline$m$ & Total amount of commodities purchased by the OEM due to natural hedging \\
\hline$w, \mu$ & Factors that describe the discount volume curve \\
\hline a & Percentage of supply costs in relation to total costs per unit for the SME-supplier \\
\hline$P_{1}$ & Price of a unit semi-finished goods \\
\hline$r_{O E M}$ & Cost reduction per unit due to volume discount \\
\hline$V_{D}$ & Value saved due to the volume discount \\
\hline
\end{tabular}

Table 2: Explanation for potential upside of financial hedge elements

\section{Potential downside of the financial options}

The internalization of a second party's financial risks is not free. There are four main potential downside elements of financial hedging:

$\Pi_{F H}^{-}=\begin{aligned} & \text { human resource costs }+ \text { hedging fees }+ \text { risk of deterioration }+ \text { steady } \\ & \text { residual risk }\end{aligned}$

Human resource costs largely depend by the OEM's prior activities in commodity purchasing and also include coordination and transaction efforts. Costs will only increase very slightly if the OEM already has personnel in place because of existing hedging activities for commodities. In this case, the focus is primarily on commodity price hedging, since most large corporations are active on a global scale and, therefore, actively hedge currency risks (Makar et al. 1999).

To develop a formula single simplifications had to be made. Firstly, a factor $u$ describes whether the OEM already hedges commodity price risks; hence, the factor will be 0 (for 'yes') or 1 (for 'no'). In both cases, the additional costs are linked to the amount to be hedged. However, human resource costs per unit will decrease sharply with rising amounts. In case the OEM does not currently hedge commodity price risk, a fixed cost component $v$ will be introduced additionally. Hence, the formula would be:

$H R_{F}=u \cdot I+\left(m^{W} \cdot \mu \cdot P_{B}\right) \cdot m \quad$ with $u=[0 ; 1]$

Hedging fees are paid per transaction. Hence, the number of transactions $z$ is multiplied by the fee $k$. However, the fee is composed of a fixed rate $k f$ per transaction and a variable rate that depends on the amount hedged. Therefore, $w$ and $\mu$ describe the decreasing cost per unit with increasing amounts and $P_{B}$ reflects the base price. 
$T F_{F}=z \cdot\left(k f+\left(m^{W} \cdot \mu \cdot P_{B}\right) \cdot m\right)$

The steady residual risk in this context is simplified. The exact residual risk demands a proper assessment of hedging tools that would go beyond the scope of the present paper. Therefore, the steady residual risk is explained as a part of the $V_{a} R_{F}$ that the OEM cannot hedge despite using hedging tools:

$$
\operatorname{VaR}_{\text {res }}=\beta \cdot \operatorname{VaR}_{F}
$$

By purchasing commodities for the SME supplier, the OEM grants its suppliers a credit since they have not yet paid. Therefore, if an SME supplier faces insolvency or for some other reason cannot purchase the commodities the OEM faces credit risk. The latter will be integrated into the model as follows:

$$
\operatorname{VaR}_{C R}=V \cdot \lambda \cdot \gamma \cdot \omega
$$

The value of the purchased commodities $v$ is multiplied by the $\lambda$ and $\gamma$, which describes the part of the value at risk. The latter is calculated by the percentage of the lost value per supplier $\lambda$ multiplied by the percentage of the supplier's usual order compared with the entire value $\gamma$. The probability of such an event occurring within the observed period is reflected in the variable $\omega$.

\begin{tabular}{ll}
\hline & Explanation \\
\hline$H R_{F}$ & Human resource costs due to natural hedging \\
$T F_{F}$ & Hedging fees depending by fixed as well as variable components \\
$V_{\text {res }}$ & Steady residual risk $\operatorname{VaR}_{F}$ which the OEM cannot hedge \\
$V_{C R} R_{C R}$ & Credit risk due to SME-supplier insolvency and/or deterioration \\
$u$ & Explains whether an OEM already has a commodity hedging team in place \\
$l$ & If the OEM does not have a commodity hedging team in place, this variable de- \\
$w, \mu$ & scribes how much would have to be invested \\
$m$ & Describe how human resource costs decrease with rising volumes \\
$P_{B}$ & Total amount of commodities purchased by the OEM due to natural hedging \\
$z$ & Base human resource cost per unit \\
$k f$ & Describes how often hedging transactions take place \\
$q$ & Describes the fixed hedging costs per transaction \\
$v$ & Describes which part of the internalized VaRF cannot be hedged by the OEM \\
$\lambda$ & Describes the total value of purchased commodities by the OEM \\
$\gamma$ & Describes the percentage of volume a certain supplier has in relation to the entire \\
$\omega$ & purchasing volume \\
\hline
\end{tabular}

Table 3: Explanation for potential downside of financial hedge elements

After having developed formulas for all the elements of the financial part of natural hedging, they must be consolidated according to the general formula presented above (Table $3)$ : 


$$
\begin{aligned}
\Pi_{F H}^{+}-\Pi_{F H}^{-}= & {\left[P_{I}+P_{1}-\left(P_{1} \cdot r_{O E M} \cdot a\right)\right] } \\
& -\left[u \cdot I+\left(m^{W} \cdot \mu \cdot P_{B}\right) \cdot m+z \cdot\left(k f+\left(m^{W} \cdot \mu \cdot P_{B}\right) \cdot m\right)\right. \\
& \left.+V a R_{\text {res }}+(v \cdot \lambda \cdot \gamma)+v \cdot \lambda \cdot \gamma \cdot \omega\right]
\end{aligned}
$$

\subsection{Physical hedge elements}

Although the financial hedge elements affect the supply risk from the SME supplier to the OEM, and thereby the supply outfall of semi-finished goods, the physical options mainly focus on securing deliveries of commodities. The main drivers of supply costs affected through natural hedging will be analyzed both in status quo situation (SQ) without natural hedging and in an advanced situation with natural hedging $(\mathrm{NH})$.

By taking over the purchasing of commodities from its suppliers, the OEM can internalize the risk of supply disruptions and the centralization of commodity supply can lead to higher efficiency in supply. The potential upsides of physical options are threefold:

- The centralization of commodity purchasing can lead to higher efficiency and lower transporting costs per unit since large amounts are transported at once.

- Since natural hedging leads to a 1:1 supply from the Tier-2 to the OEM, transaction costs, coordination costs and ultimately human resource costs can be saved.

- Centralized purchasing and inventory can diminish inventory costs through natural hedging. In addition, SME suppliers can profit from delivery on demand because of the short distance to the OEM.

The potential downsides of physical hedging are:

- The natural hedging approach allows the OEM to redistribute and allocate resources according to its own priorities. However, the redistribution to all the suppliers leads to additional transportation costs.

- The physical options lead to a significant rise in human resources in supply chain management. The OEM will need additional resources in purchasing and inventory management. Further, natural hedging calls for higher coordination efforts to manage the purchasing process and to organize the allocation of the purchased resources.

- Because the OEM purchases and distributes the commodity in a centralized purchasing model, additional inventory costs arise since it must store the commodities before redistributing them.

Based on these potential upsides and downsides, the model will be developed according to the comparison of a status quo (SQ) situation and a situation with natural hedging $(\mathrm{NH})$ :

$$
\begin{aligned}
& \Pi_{S C}^{S Q}-\Pi_{S C}^{N H}=\begin{array}{l}
\text { (transportation costs } \mathrm{SQ}-\text { transportation costs } \mathrm{NH})+ \\
(\text { inventory costs } \mathrm{SQ}-\text { inventory costs } \mathrm{NH})+
\end{array} \\
& \text { (HR costs SQ - HR costs NH) }
\end{aligned}
$$

At the core of the physical elements of natural hedging is the centralization of purchasing. The model will thereby combine possible costs such as human resources, inventory and transportation. In this context, a comparison between the status quo and the implementation of physical hedge elements will be integrated to find out whether efficiencies are possible because of the bundling of supplies. 


\section{Transportation efficiencies}

This part will compare transportation costs in the status quo situation (SQ) with transportation costs under the natural hedging approach $(\mathrm{NH})$. In the $\mathrm{SQ}$, commodities are purchased according to a flexible single source supply arrangement (Tomlin/Wang 2005). Hence, the assumption for the model is that all SME suppliers purchase their commodity demands from the same commodity supplier. In this case with $n$ suppliers:

$S_{N}=\left[S_{1}, S_{2}, S_{3}, \ldots, S_{n}\right]$

In the present model, transportation costs depend on amounts to be transported and the distance. SME suppliers have individual demands $m_{N}$ and distances $y_{N}$ :

$m_{N}=\left[m_{1}, m_{2}, m_{3}, \ldots, m_{n}\right]$

$y_{N}=\left[y_{1}, y_{2}, y_{3}, \ldots, y_{n}\right]$

Further, a simplifying assumption is made. The model retains that transportation costs per unit slightly decrease with rising amounts of transported goods. Transportation costs per unit $e$ are calculated as follows:

$e_{N}=m_{n}{ }^{W} \cdot \mu \cdot P_{B} \quad$ with $-1<w<0$

A further component of transportation costs is the distance to the SME supplier. Hence, the variable cost per distance $f$ must be integrated and multiplied by the distance $y$ to calculate transportation costs. However, scale effects are not applicable in this context. The variable $f$ is composed by several costs such as fuel costs, highway tolls, driver time and so on. However, this differentiation will not be included in the model. The transportation cost for $S_{N}$ is thereby:

$T_{n}=\left(m_{n} \cdot e_{n}\right)+\left(y_{n} \cdot f\right)$

To calculate the total costs for the transportation of all suppliers $S_{N}$ the transportation costs of each supplier must be added:

$$
T_{S N}=\sum_{n=1}^{n}\left(\left(m_{n} \cdot e_{n}\right)+\left(y_{n} \cdot f\right)\right)
$$

This formula only covers the transportation from the commodity supplier to the SME supplier. The supply of semi-finished goods from the SME supplier to the OEM remains the same despite the implementation of natural hedging. Hence, it can be left out since the model analyzes the difference in costs.

Natural hedging provides a different constellation because of centralized purchasing. In this case, purchasing follows a dedicated single source supply (Tomlin/Wang 2005). The bundled supply to the OEM can be described with the following formula and the only difference is that there is only one calculation since it is a 1:1 supply:

$T_{\text {OEM } 1}=(m \cdot e)+(y \cdot f)$ 
After having received the commodities from the Tier-2 supplier, the OEM now has to redistribute the goods to all its suppliers. Again, the principle is equal to formula (22):

$$
T_{\text {OEM }}=\sum_{n=1}^{n}\left(m_{n} \cdot e_{n}\right)+\left(y_{n} \cdot f\right)
$$

To compare the transportation costs the different components must be combined by subtracting the costs in the status quo from the costs from natural hedging (Table 4).

Transportation costs $\mathrm{SQ}-$ Transportation costs $\mathrm{NH}=$

$\sum_{n=1}^{n}\left(\left(m_{n} \cdot e_{n}\right)+\left(y_{n} \cdot f\right)\right)-(m \cdot e)+(y \cdot f)+\sum_{n=1}^{n}\left(\left(m_{n} \cdot e_{n}\right)+\left(y_{n} \cdot f\right)\right)$

if $<0 \rightarrow$ additional costs because of natural hedging

if $>0 \rightarrow$ gains because of higher efficiency

\begin{tabular}{ll}
\hline & Explanation \\
\hline$T_{N}$ & Transport costs from the commodity supplier to the SME-supplier (SQ) \\
$T_{O E M 1}$ & Transport costs from the commodity supplier to the OEM (NH) \\
$T_{O E M}$ & Transport costs from the OEM to the SME-supplier (NH) \\
$m$ & Total amount of commodities purchased by the OEM due to natural hedging \\
$m_{n}$ & Total amount of commodities purchased by the SME-supplier \\
$w, \mu$ & Describe how transport costs decrease with rising volumes \\
$P_{B}$ & Base transport cost per unit \\
$e_{n}$ & Transport cost per unit \\
$y$ & Distance from to the OEM \\
$y_{n}$ & Distances to the SME-supplier \\
$f$ & Cost per distance (km) \\
\hline
\end{tabular}

Table 4: Explanations for transport costs

\section{Human resources efficiencies}

This part will compare human resource costs in the status quo with human resource costs in the natural hedging situation. Human resource costs are assumed for managing the inbound supply chain. In other words, human resource costs do not include salaries for truck drivers, inventory personnel, and so on. They rather comprise personnel in logistics management that coordinates the purchasing process. The main assumption in this case is that human resource costs, as well as coordination and transaction costs, are influenced by the purchasing amount $m$.

In the status quo, SME suppliers $\left(S_{n}\right)$ each purchase a specific amount $m_{n}$ to produce semi-finished goods and supply the OEM. In this case, all SME suppliers have their own purchasing teams. Since the human resource cost per unit sinks in a non-linear way with rising amounts, they must be calculated as follows:

$g_{n}=m_{n}{ }^{W} \cdot \mu \cdot P_{B} \quad$ with $-1<w<0$ 
Hence, the cost per SME supplier will be:

$H R_{n}=m_{n} \cdot g_{n}$

The total human resource costs of all SME suppliers are thereby:

$H R_{N}=\sum_{n=1}^{n} m_{n} \cdot g_{n}$

The supply of semi-finished goods from the SME supplier to the OEM remains the same despite the implementation of natural hedging. Hence, it can be left out since the model analyzes the difference in costs.

Owing to the centralization of commodity supply within the scope of physical hedging, the OEM must extend its human resource costs in supply chain management. Again, the additional costs will depend on the managed amount of commodities. Therefore, the costs for the supply from the Tier-2 supplier are:

$H R_{O E M}=m \cdot g$

Once the OEM has received the commodities, it will distribute them according to the SME suppliers' needs. Therefore, the human resource costs of the supplier must be added.

The comparison of human resource costs in SQ as well as in NH provides the following formula (Table 5):

$\mathrm{HR}$ costs $\mathrm{SQ}-\mathrm{HR}$ costs $\mathrm{NH}=\sum_{n=1}^{n} m_{n} \cdot g_{n}-(m \cdot g)+\sum_{n=1}^{n} m_{n} \cdot g_{n}$

if $<0 \rightarrow$ additional costs because of natural hedging

if $>0 \rightarrow$ gains because of higher efficiency

\begin{tabular}{ll}
\hline & Explanation \\
\hline$H R_{N}$ & $\begin{array}{l}\text { Human resource (incl. transaction and coordination costs) of the SME-supplier } \\
\text { (SQ) }\end{array}$ \\
$H R_{O E M 1}$ & Human resource (incl. transaction and coordination costs) of the OEM (NH) \\
$H R_{O E M}$ & $\begin{array}{l}\text { Human resource (incl. transaction and coordination costs) of the SME-supplier } \\
\text { (NH) }\end{array}$ \\
$m_{n}$ & Total amount of commodities purchased by the OEM due to natural hedging \\
$w, \mu$ & Total amount of commodities purchased by the SME-supplier \\
$P_{B}$ & Describe how human resource costs decrease with rising volumes \\
$g_{n}$ & Base human resource costs per unit \\
\hline
\end{tabular}

Table 5: Explanations for human resource costs

\section{Inventory efficiencies}

This final part will compare inventory costs in the status quo with inventory costs in the natural hedging situation. It will additionally analyze how inventory costs differ in the status quo and under natural hedging. Inventory costs are mainly driven by the amount $m$ of 
goods and the time of storage $t$. In the SQ, commodities are separately purchased by the SME supplier for production. Each SME supplier has its own demand; therefore, formulas (19) and (20) are applicable in this context. Concerning inventory price per unit $h$, a simplifying assumption will be made. With increasing amounts $\left(m_{n}\right) h$ decreases slightly:

$h_{n}=m_{n}{ }^{W} \cdot \mu \cdot P_{B} \quad$ with $-1<w<0$

A further driver of inventory costs are capital costs bound to the goods held in stock. Usually, the weighted average cost of capital WACC is implied in the calculation (Hutchison et al. 2009). In addition, inventory costs rise the longer goods are stored. Therefore, costs per $t(j)$ must be multiplied as the duration of storage extends. The inventory costs in the status quo are thereby:

$I_{N}=\sum_{n=1}^{n}\left(\left(m_{n} \cdot h_{n}\right)+\left(t_{n} \cdot j\right)\right) \cdot W A C C$

Natural hedging leads to increased inventory costs since the OEM is not involved in purchasing commodities. In the NH situation, the OEM is obliged to store commodities to then redistribute them to SME suppliers. The OEM faces additional inventory costs:

$I_{O E M}=\left(\sum_{n=1}^{n}\left(\left(m_{n} \cdot h_{n}\right)+\left(t_{n} \cdot j\right)\right)+(m \cdot h)+(t \cdot j)\right) \cdot W A C C$

The SME suppliers' inventory costs must be integrated since they still have to store the commodities before production. However, there are possibilities of supplying on demand, for instance according to just-in-time principles. Hence, the variable $t$ could be a strong driver for these inventory costs since low storage durations will lead to lower inventory costs.

Comparing inventory costs leads to the following formula (Table 6):

Inventory costs $\mathrm{SQ}$ - Inventory costs $\mathrm{NH}=$

$\sum_{\mathrm{n}=1}^{\mathrm{n}}\left(\left(\mathrm{m}_{\mathrm{n}} \cdot h_{n}\right)+\left(t_{n} \cdot j\right)\right) \cdot W A C C-\sum_{n=1}^{n}\left(\left(\left(m_{n} \cdot h_{n}\right)+\left(t_{n} \cdot j\right)\right)+(m \cdot h)+(t \cdot j)\right) \cdot W A C C$

if $<0 \rightarrow$ additional costs because of natural hedging

if $>0 \rightarrow$ gains because of higher efficiency 


\section{Explanation}

$I_{N} \quad$ Inventory costs of the SME-supplier (SQ)

I OEM $1 \quad$ Inventory costs of the OEM (NH)

$I_{O E M} \quad$ Inventory costs of the SME-supplier $(\mathrm{NH})$

$m \quad$ Total amount of commodities purchased by the OEM due to natural hedging

$m_{n} \quad$ Total amount of commodities purchased by the SME-supplier

$w, \mu \quad$ Describe how transport costs decrease with rising volumes

$P_{B} \quad$ Base transport cost per unit

$h_{n} \quad$ Inventory cost per unit

$y \quad$ Inventory duration at the OEM

$y_{n} \quad$ Inventory duration at the SME-supplier

$f \quad$ Cost per time unit (day)

WACC Weighted average cost of capital

Table 6: Explanations for inventory costs

After having developed the single elements of the natural hedging model, the single elements are consolidated. Table 7 provides a basis for the scenario analysis in the next section.

\begin{tabular}{|c|}
\hline Financial elements of natural hedging \\
\hline $\begin{array}{c}\left(p_{1}+V_{D}\right)-\left(H R_{F}+T F_{F}+V a R_{r e s}+V a R_{C R}\right)= \\
\left(P_{I}+P_{1}-\left(P_{1} \cdot r_{O E M} \cdot a\right)\right)- \\
\left(u \cdot I+\left(m^{w} \cdot \mu \cdot P_{B}\right) \cdot m+z \cdot\left(k f+\left(m^{w} \cdot \mu \cdot P_{B}\right) \cdot m\right)+V a R_{r e s}+(v \cdot \lambda \cdot \gamma)+v \cdot \lambda \cdot \gamma \cdot \omega\right)\end{array}$ \\
\hline Physical elements of natural hedging \\
\hline $\begin{array}{c}T_{N}-\left(T_{\text {OEM } 1}+T_{\text {OEM }}\right)= \\
\sum\left(\left(m_{n} \cdot e_{n}\right)+\left(y_{n} \cdot f\right)\right)-(m \cdot e)+(y \cdot f)+\sum\left(\left(m_{n} \cdot e_{n}\right)+\left(y_{n} \cdot f\right)\right)\end{array}$ \\
\hline $\begin{array}{l}H R_{n}-\left(H R_{O E M 1}+H R_{O E M}\right)= \\
\sum m_{n} \cdot \mathrm{g}_{\mathrm{n}}-(m \cdot \mathrm{g})+\sum \mathrm{m}_{\mathrm{n}} \cdot \mathrm{g}_{\mathrm{n}}\end{array}$ \\
\hline $\begin{array}{c}I_{n}-\left(I_{\text {OEM } 1}+I_{\text {OEM }}\right)= \\
\left(\left(m_{n} \cdot \mathrm{h}_{\mathrm{n}}\right)+\left(\mathrm{t}_{\mathrm{n}} \cdot \mathrm{j}\right)\right) \cdot \text { WACC }-\sum\left(\left(\left(\mathrm{m}_{\mathrm{n}} \cdot \mathrm{h}_{\mathrm{n}}\right)+\left(\mathrm{t}_{\mathrm{n}} \cdot \mathrm{j}\right)\right)+(\mathrm{m} \cdot \mathrm{h})+(\mathrm{t} \cdot \mathrm{j})\right) \cdot \text { WACC }\end{array}$ \\
\hline
\end{tabular}

Table 7: Conjunctions of natural hedging elements

To outline the scenario analysis a simple method was applied using Excel spreadsheets. After having connected all the variables according to the developed formulas, estimates were made for the independent variables that were fixed. While changing only the purchasing volume within the scenario, the dependent variables were observed. The focus was on the components depicted in Figure 2. The goal of the scenario was not to present exact 
calculations of costs or benefits but rather to explain the dynamics of natural hedging in the context of a sensitivity analysis.

Financial elements of natural hedging

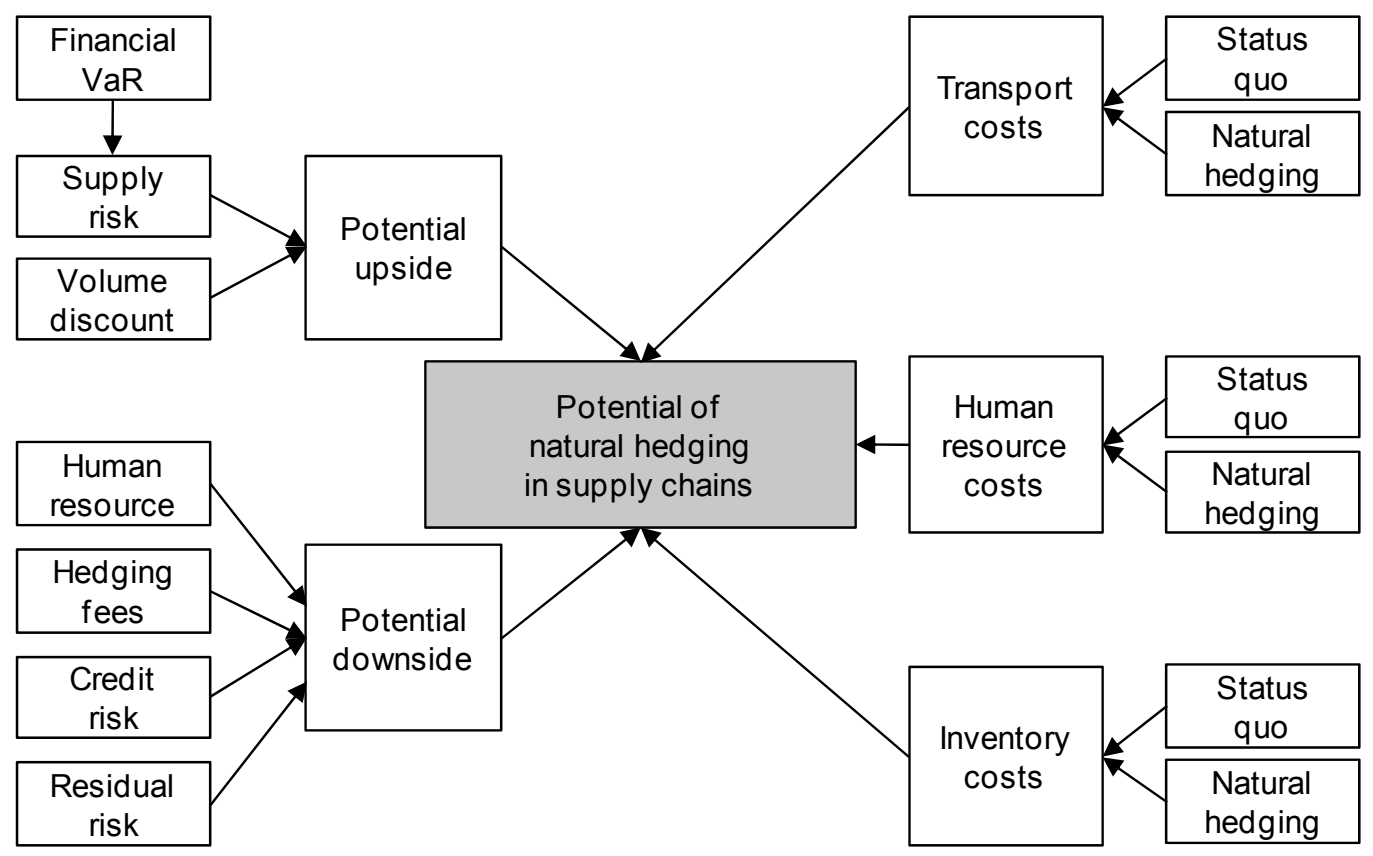

Figure 2: Objects of analysis and their interdependencies in natural hedging

\section{Scenario analysis}

\subsection{Assumptions of the international supply chain scenario}

By briefly addressing the single objects of analysis, the main assumptions and the context in which the scenario took place are now presented. The numbers in the brackets represent the formula in which the specific assumption was made. The other assumptions can be found in the Appendix:

- To calculate the $\operatorname{VaR}_{F}$ figures two different years were analyzed. Hence, volatilities and the correlation factor are based on the most recent data. The calculation applies a confidence interval of $95 \%$. Currency data has its source in US dollar/Euro data (2007 and 2008) and steel was chosen as an example of a commodity. (5)

- For the supply risk calculation the assumption was made that the OEM holds one month of semi-finished goods in stock, thereby $1 / 12$ of the entire amount. (7)

- The OEM is assumed not to pursue commodity hedging activities. (13)

- The OEM is able to hedge $99 \%$ of the $\operatorname{VaR}_{F}$. (15)

- The scenario assumes there are seven SME suppliers and that each of them orders the same amount, thereby $m / n$. $(19,20)$ 
- The distance between the commodity supplier and the OEM and SME supplier is assumed to be 9'000 km and the distance between the OEM and SME supplier $300 \mathrm{~km}$. This assumption is based on the example of the automobile industry where suppliers are traditionally located around the OEM. (24)

- Base transport costs per unit between the OEM and SME supplier are assumed to be smaller than those from the commodity supplier to the SME supplier. This is because of the fact that thanks to the significantly smaller distance, there is much higher flexibility concerning disruptions or glitches. (26)

- Human resource and coordination base costs per unit are also assumed to be lower for the SME supplier with the implementation of natural hedging since it only has to deal with one company in contrast to the status quo where the SME supplier depends on a third party (the Tier-2). (32)

- Inventory base costs per unit are also supposed to be lower in NH than in the status quo (SQ). Natural hedging enhances the cooperation and coordination between the SME supplier and the OEM. Hence, supply can be managed more efficiently and closer to actual market demands. This is also enabled through the smaller distance between the OEM and the SME supplier. Therefore, the latter will not have to keep commodities in stock for as long as in the status quo.

- Prices are roughly estimated and are not meant to be exactly realistic. The focus lies on the relative correctness of the figures. (36)

- The decreasing marginal costs were largely applied in the formulas. Certain costs converged towards $35 \%$ of the base cost, whereas others converged towards $50 \%$ or $75 \%$ of the base cost per unit.

With these assumptions integrated into the model, the purchasing volume was driven from an initial point of $80^{\prime} 000$ to $2^{\prime} 400^{\prime} 000$ in steps of $80^{\prime} 000$. The implications for natural hedging in international supply chains and its financial and physical options will be presented now.

\subsection{Purchasing volume scenario}

This specific scenario was chosen because of the significant impact that the amount of purchased commodities has on the model and thereby the dynamics of natural hedging. Many variable cost components depend on the amount of purchased commodity goods. On the one hand, it seems obvious that the implementation of natural hedging implies additional costs because of a rise in transportation, inventory and human resource costs. On the other hand, purchasing a substantially higher amount of commodities for multiple suppliers in one order over the OEM can lead to economies of scale. Hence, the hypothesis in this scenario would be that natural hedging becomes more attractive with higher purchasing volumes.

The presentation of the results will proceed from single components to the overall assessment and it will be illustrated with graphs and tables. The financial element of natural hedging presents itself in Table 8 . 


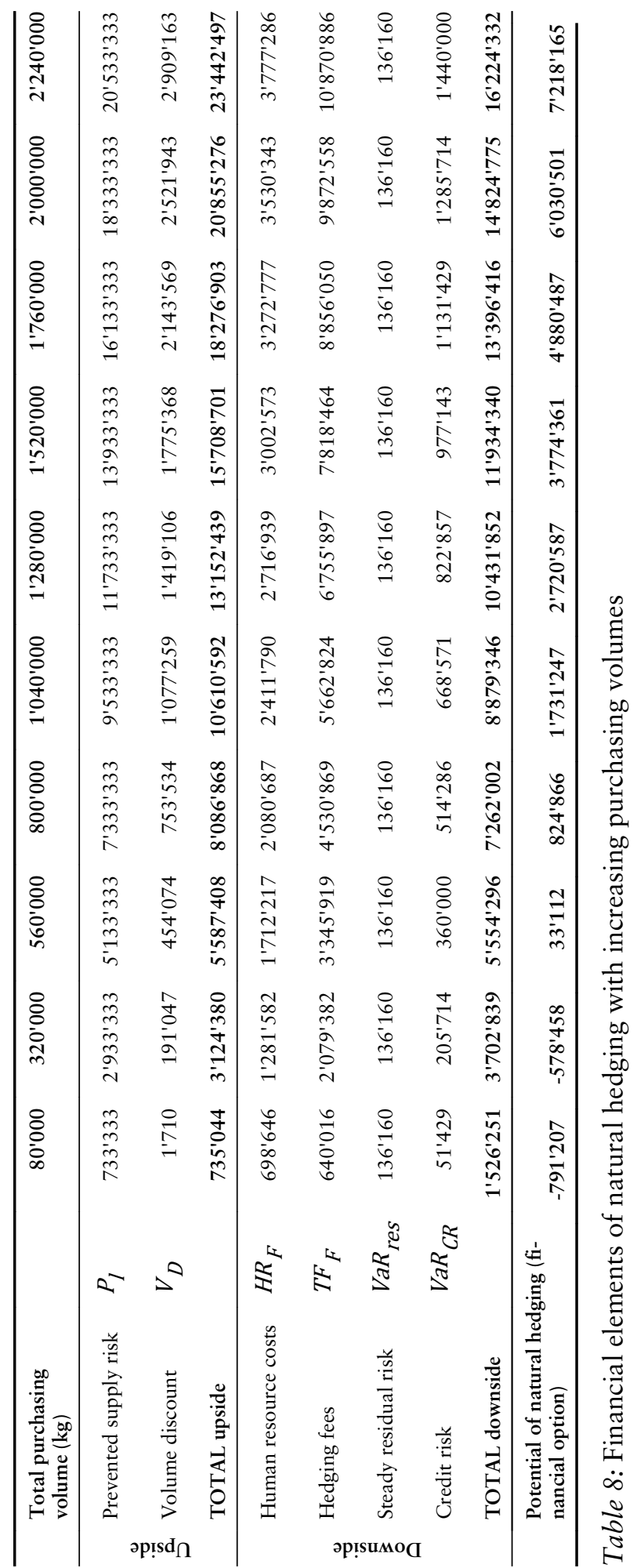




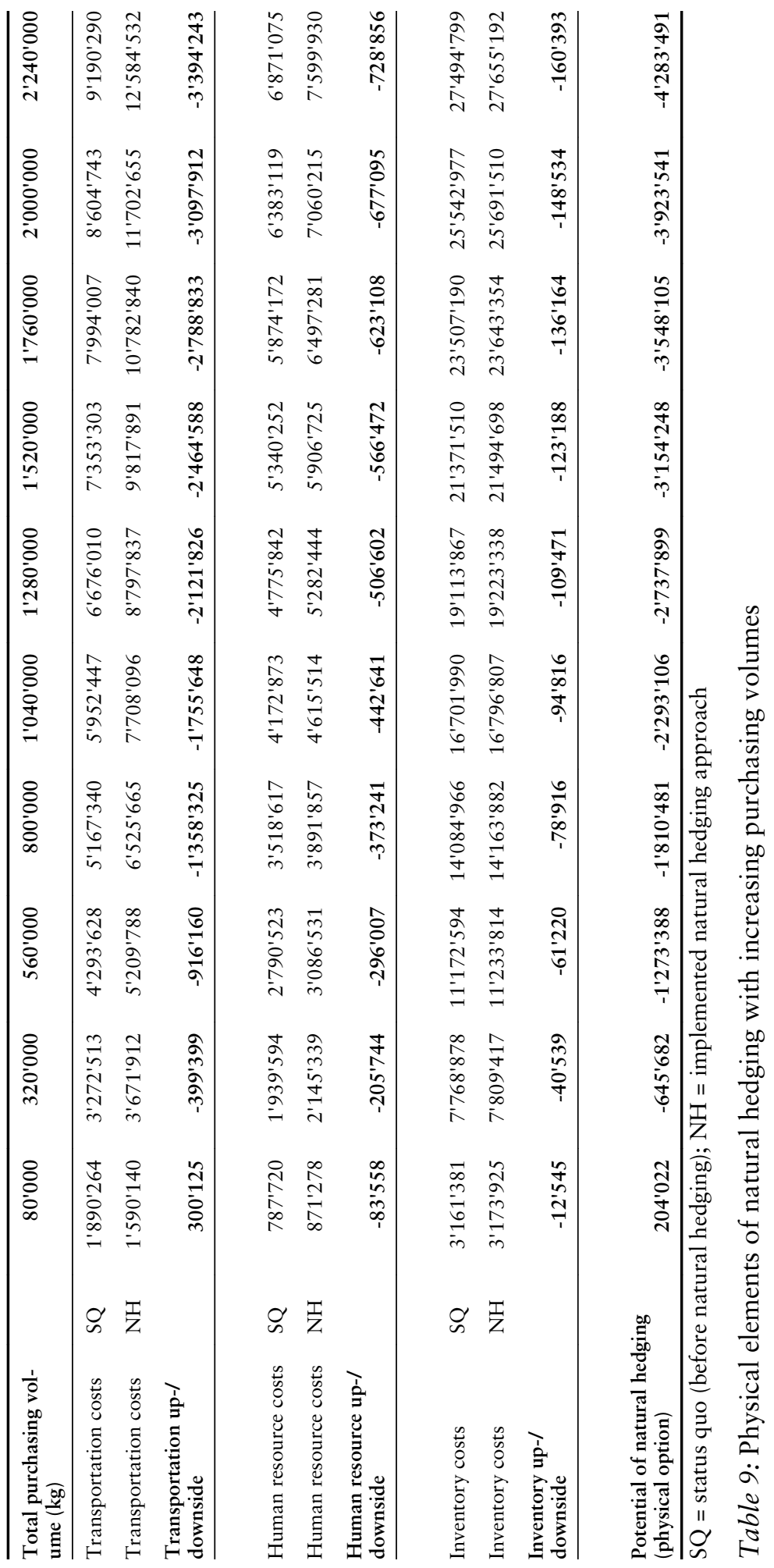


The upside of the financial elements of natural hedging consists of prevented supply losses because of the hedging itself and volume discounts. The supply risk prevention accounts for the largest part of the upside. Up- and downside potentials are measured in Euro.

Combining both up- and downside shows that the financial perspective of natural hedging has significant potential, especially with high volumes. As evidenced in Figure 3 at an amount of approximately 550'000 units the upside exceeds the downside.

Financial elements of natural hedging depending on purchasing volume

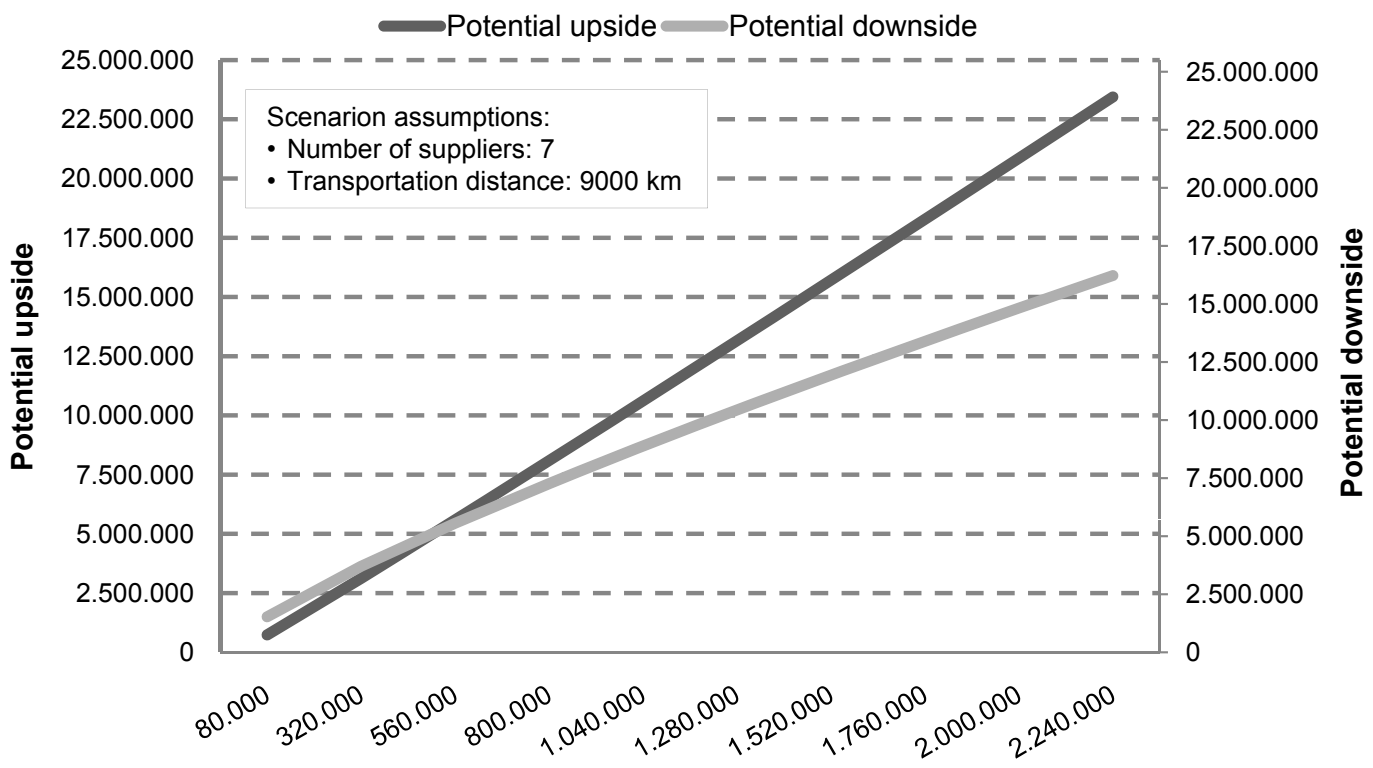

Purchasing volume

Figure 3: Up- and downsides of financial elements of natural hedging as a function of purchasing volume

The physical element of natural hedging shows a slightly different picture. Table 9 depicts the supply cost categories and their respective costs in the status quo and after the implementation of natural hedging.

A different view of the analysis on the physical element is provided by Figure 4. It shows supply costs before and after the implementation of natural hedging.

The conjunction of both parts to the concept of natural hedging reveals interesting facts. Figure 5 shows how the upside coming from the financial element of natural hedging develops in comparison to the downside coming from the physical part with increasing purchasing volumes.

The analyses show how potential decreases start from small purchasing volumes. However, the minimum is reached at approximately 550'000 units and although marginal costs decrease, the upside increases at a high rate to find positive potential for natural hedging at approximately 1'400'000 units.

The scenario of rising purchasing volumes has shown two different effects. Although the financial perspective enhanced the upside of natural hedging, the physical element seemed 
Supply costs before (SQ) and after the implementation of natural hedging $(\mathrm{NH})$ depending on purchasing volume

Supply costs NH Supply costs SQ

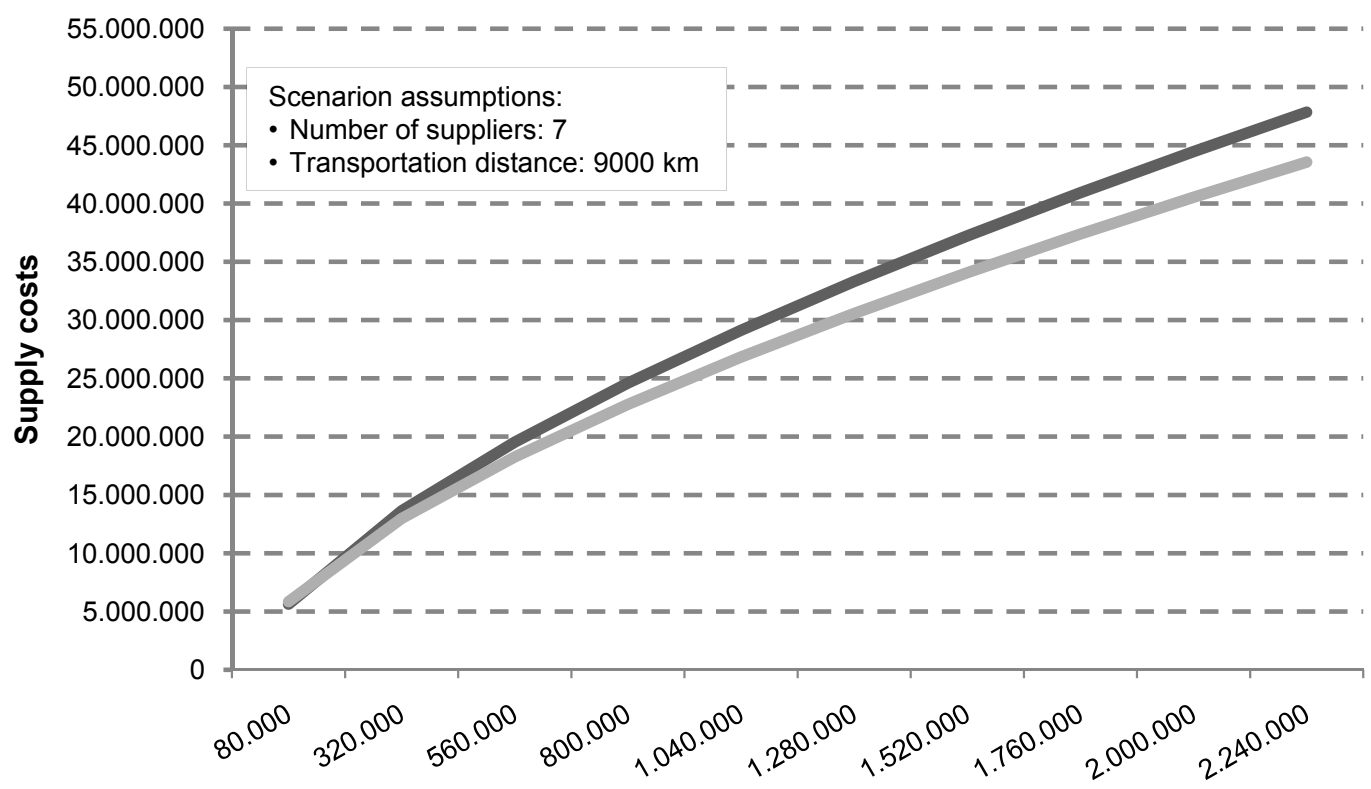

Purchasing volume

Figure 4: Supply costs before and after the implementation of natural hedging

to have the opposite effect. However, the increase of the downside clearly slows down significantly with higher purchasing volumes. The analyses showed that the upside overpowers the downside and - especially at high volumes - natural hedging has considerable potential.

How is it though that the physical option provides such a negative development? The scenario illustrates that the main driver of the exceeding costs with natural hedging is transportation. Indeed, in practice the purchased commodities would in fact travel farther if purchased under a centralized supply concept. However, the scenario does not foresee a change in distances and despite this transportation costs still rise. The reason lies in the fact that the scale effects are eliminated by the additional costs to transport the commodities from the OEM back to each SME supplier. This scenario proves that potential natural hedging does increase with higher purchasing volumes. Owing to the findings of this analysis, it becomes crucial to find out how the objects of analysis change with an altering number of suppliers or different distances. 


\section{Potential of natural hedging (financial element) in comparison with additional supply costs depending on purchasing volume}

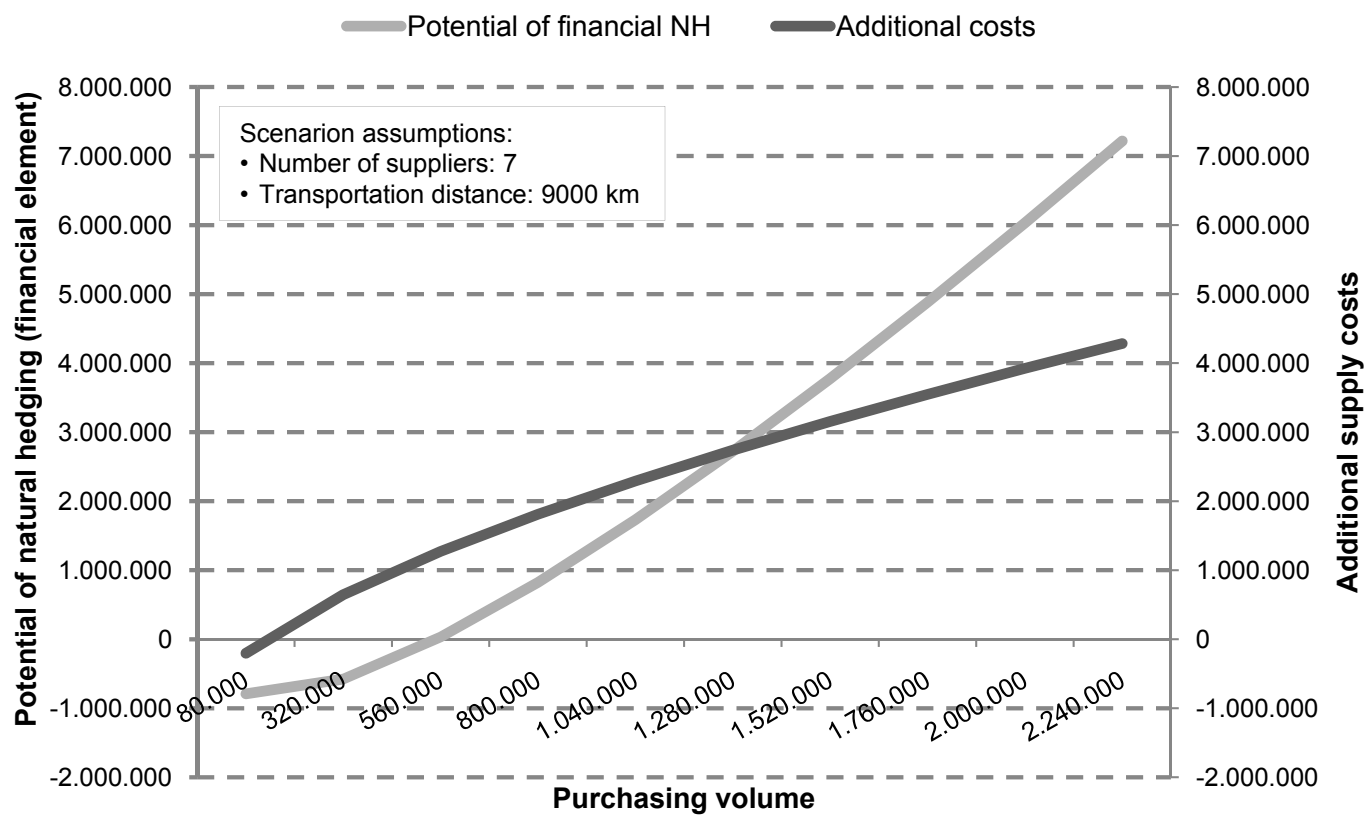

Figure 5: Upside and downside potential of natural hedging as a function of purchasing volume

\subsection{Discussion}

The purchasing volume scenario has shown that natural hedging can have a positive impact on international supply chains. Nonetheless, certain reflections must be made concerning the plausibility of the obtained results. The scenario, for instance, exhibited two different pictures. On the one hand, the financial option showed a clear upside potential but, on the other hand, supply costs seemed to grow with rising purchasing amounts. The question at this point is whether the physical option actually makes sense. However, this is only one perspective of the concept. Future scenarios should focus on the number of suppliers and transportation distances. In fact, applying natural hedging seems advantageous with a higher number of suppliers and with a greater distance between the SME suppliers and the OEM. Practitioners, however, might question this conclusion. Having many suppliers can theoretically enhance the potential for natural hedging but it also implies higher coordination and transportation costs. The amount for each supplier would also shrink, thereby endangering the existence of an SME supplier for instance. The transportation costs effect is rooted in the fact that natural hedging implies only one (or a few) route(s) with higher freight volumes instead of $n$ routes to the SME suppliers with low freight volumes. On the basis of the scenario analysis, the central factors for practitioners deciding whether to implement natural hedging are the following: 
- High volumes are favourable in the context of natural hedging. It is necessary though that supply costs are kept under control, especially concerning transportation since they have a significant impact.

- A supply chain with multiple suppliers provides a good platform for the implementation of natural hedging. The centralization of commodity purchasing would provide positive scale effects. However, coordination costs must be taken into consideration when seeking a high number of suppliers.

- Applying natural hedging in a supply chain constellation, which sees commodity suppliers close to both the SME supplier and OEM, makes little sense. Positive scale effects are achievable in a situation where a commodity supplier must transport goods to several SME suppliers according to single orders and on long distances. In this case, natural hedging centralizes the supply into one order and thereby costs can be saved.

The presented results from the scenario analysis are based on specific assumptions. However, in the context of the present paper simplifications had to be made. In the financial option, for instance, the paper deliberately omitted complex financial argumentations and limited the formulas to simple value-at-risk calculations. Although the financial valueat-risk was calculated in detail, other variables such as credit risk and residual risk were starkly simplified by integrating specific factors. A more in-depth analysis of forward transactions would provide more reliable formulas for the model. In addition, the variable $F_{S}$ was significantly simplified by defining it as the value-at-risk level at which the SME supplier cannot cope with the risk and becomes insolvent. This factor would have to be differentiated by integrating a further model for the SME supplier that exhibits its vulnerability and financial status. This, however, would go beyond the scope of the present paper, which legitimizes the variable $F_{s}$. Further, no differentiation was made between several commodities or currencies. In particular, concerning commodity hedging a more detailed analysis would provide further insights since the hedging strategy also depends on what kind of product must be hedged (Lee 2002). The physical option of natural hedging was also subject to simplifications. Scale factors as well as base prices had to be roughly estimated. In addition, the selection of supply cost components can be questioned. However, the model aims at illustrating the principle and the dynamics of natural hedging, which is why the paper focuses on the most significant elements.

The scenario analysis merely provided one main input variable and thereby one perspective on the concept. With appropriate software and an enhanced model, the scenario analysis could comprise simultaneous changes of several variables. These kinds of tools also enable defining a specific optimal point for each input variable. Apart from additional software, optimal points can be found by using mathematical derivation to find maximum or minimum points within a scenario. The presented model can provide information on the effect of further input variables.

Finally, the general approach could also be criticized. A formal analytical analysis was chosen to be able to assess the dynamics and interdependencies of the natural hedging concept. One could argue, however, that the lack of a practical approach provides unreliable results. To assess the most important drivers of natural hedging the analytical method 
answered the purpose and provided a model that can then be used for further research and practical work such as specific interviews with company employees.

\section{Conclusion}

The results of this paper consisting of a brief literature review, an analytical model and a scenario analysis showed that the ability to cooperatively bundle different risks of multiple interacting supply chain actors could be seen as a concrete strength of natural hedging in international supply chains. Therefore, the concept lives up to the ideals of an integrated and proactive risk management approach at a network level (Harland et al. 2003). As natural hedging can reduce the vulnerability in the supply chain, the paper offered some insights into the mechanisms of the concept. SME suppliers that lack both management and financial resources are actively supported by the OEM. However, the approach cannot be based on goodwill. The main goal is to avoid supply chain disruptions by reducing the SME supplier's vulnerability. By taking over currency risk as well as price volatility risk the OEM internalizes financial risks and hedges them with existing tools such as forwards, futures or options. Additionally, the OEM goes a step further and physically purchases specific commodities for its suppliers in the context of centralized purchasing. These commodities can then be redistributed according to demand. Hence, natural hedging as a specific tool for supply chain risk management can reduce external financial risks and secure supplies by reducing supply chain disruptions for the entire supply chain (network).

Apart from the findings of the model and scenario analysis, the implication of natural hedging must take the mainly qualitative strengths and weaknesses of the concept into account. In the process of the present paper, the strengths of natural hedging have been addressed. Since the concept has its source in supply chain risk management, it suggests itself to start out with risk reduction. With the initial intent to free a vulnerable SME supplier of its financial risks, other risks can indirectly be reduced simultaneously. By diminishing the vulnerability concerning market risks on the supply side, natural hedging also reduces the risk of supply chain disruption, which can be a major cause of SME insolvency. A further side effect is that an OEM usually has higher purchasing power. Hence, it can secure supply from a commodity supplier, whereas an SME supplier that only demands a small amount is a lower priority in times of short supply. In connection with this centralized purchasing approach, the OEM automatically purchases higher volumes and - as the scenario has shown - can thereby generate volume discounts and scale economies throughout the commodity supply process. Centralized supply, however, brings further advantages that were not included in the model. By possessing of all the commodities, the OEM can take control of the supply situation to the SME suppliers. Hence, the OEM has the freedom to decide which supplier receives what amount of commodities according to actual demand and prioritization. As can be observed in the automotive industry, for instance, geographical closeness enables enhanced supply strategies such as just-in-time. Even though these kinds of strategies are mostly applied to the supply of semi-finished goods in the automobile production, similar approaches can be pursued with natural hedging. According to its own demands, the OEM can thus plan its own supply of semi-finished goods by managing the commodity supply to the SMEs. This idea is underlined by Stein (1997) who introduces the term 'winner picking' in the context of internal capital markets. He examines the role of corporate headquarters in allocating scarce resources to competing projects in an internal capital market. 
In addition to the significant strengths and potentials, natural hedging in international supply chains also has weaknesses. First, natural hedging cannot be implemented in any context. The scenario analysis showed that high purchasing volumes as well as multiple suppliers and relatively long transportation distances must be in place to enable the potential of natural hedging. Implementing natural hedging in an international supply chain requires long-term planning in terms of negotiation, change management and process restructuring. In fast-moving markets where supply chains change continuously, natural hedging would have already failed in the implementation phase. Hence, it requires longterm supplier-customer relationships. Further, the concept makes little sense for commodities with a low value in production or for commodities that are easily substitutable. Finally, it is crucial to keep additional costs in consideration. Natural hedging requires higher coordination costs and as the scenario analysis has shown all upside arguments about risk reduction can end up having little meaning in the short run if costs cannot be controlled and efficiencies cannot be achieved. Hence, if a company does not succeed in capitalizing on scale effects natural hedging will be destined to fail. Furthermore, once natural hedging is implemented it cannot be easily reversed. This requires a profound analysis of the upand downside potential of natural hedging. This paper serves as a basis to do so; however, further research on this matter must follow to better understand the complexity of natural hedging.

To analyse in detail the potential of natural hedging for a specific company or supply chain the single elements of the financial and physical hedge elements must examined one by one. For example, it is crucial to include exact hedging-related calculations according to current practice. In general, single variables must be researched on the basis of empirical analysis and expert interviews to obtain a practical and holistic view. A next step would then be to assess the implementation process against the background of change management and process restructuring. Usually, limitations are faced in the initial and implementation phases. Finally, further research should aim at a differentiation of potential analysis for different industries. For instance, instead of focusing on the automobile industry it would be interesting to assess the potential of natural hedging in the pharmaceutical or semiconductor industry. 


\section{Appendix}

\begin{tabular}{|c|c|c|}
\hline Variable & Explanation & Scenario assumption \\
\hline $\operatorname{VaR}_{F}$ & $\begin{array}{l}\text { Potential, maximal financial loss of the portfolio com- } \\
\text { posed of currency and commodity price } V a R \text { at confi- } \\
\text { dence interval of } \alpha\end{array}$ & Dependent \\
\hline $\operatorname{VaR}_{p}$ & $\begin{array}{l}\text { Potential, maximal financial loss for on commodity price } \\
\text { purchase at a confidence interval of } \alpha \text {, a volatility of } \sigma_{p} \text {, } \\
\text { and a value of } V_{t}\end{array}$ & Dependent \\
\hline $\operatorname{VaR}_{c}$ & $\begin{array}{l}\text { Potential, maximal financial loss on currency volatility a } \\
\text { confidence interval of } \alpha \text {, a volatility of } \sigma_{c} \text {, and a value of } \\
f_{x} t\end{array}$ & Dependent \\
\hline$z_{\alpha}$ & $\begin{array}{l}\text { Scaling factor at a confidence interval of } \alpha \text { and the as- } \\
\text { sumption of a normal distribution }\end{array}$ & $1.65(95 \%)$ \\
\hline$\sigma_{p}$ & $\begin{array}{l}\text { Volatility of commodity price over period of analysis (one } \\
\text { year) }\end{array}$ & $12 \%$ \\
\hline$\sigma_{c}$ & $\begin{array}{l}\text { Volatility of exchange rate over period of analysis (one } \\
\text { year) }\end{array}$ & $7 \%$ \\
\hline$k_{c, p}$ & Correlation factor between currency and commodity price & 0.68 \\
\hline$f x_{t}$ & Initial commodity price & 1.5 \\
\hline$V_{t}$ & Initial exchange rate & 500 \\
\hline$F_{S}$ & $\begin{array}{l}\text { Represents the } \operatorname{VaR}_{F} \text { at which the SME-supplier can't } \\
\text { cope with the financial loss due to currency and price risk } \\
\text { and becomes insolvent }\end{array}$ & $500 ’ 000$ \\
\hline$s$ & $\begin{array}{l}\text { Amount of semi-finished goods that the OEM holds on } \\
\text { stock }\end{array}$ & 6667 \\
\hline Y & $\begin{array}{l}\text { Amount of semi-finished goods which the SME-supplier is } \\
\text { supposed to deliver but cannot due to } \operatorname{VaR}_{F}>F_{S}\end{array}$ & Input to scenario \\
\hline$\varphi$ & $\begin{array}{l}\text { Factor which describes how much the OEM holds on } \\
\text { stock }\end{array}$ & \\
\hline$y_{1}$ & $\begin{array}{l}\text { Amount of semi-finished goods lost due to the SME-sup- } \\
\text { plier's insolvency (minus stock) }\end{array}$ & Dependent \\
\hline$p_{u}$ & Profit the OEM makes per unit of semi-finished goods & 10 \\
\hline$P_{1}$ & Total profit loss due to SME-supplier's insolvency & Dependent \\
\hline$m$ & $\begin{array}{l}\text { Total amount of commodities purchased by the OEM due } \\
\text { to natural hedging }\end{array}$ & Input to scenario \\
\hline$w, \mu$ & Factors that describe the discount volume curve & $-0.085,2.6$ \\
\hline$a$ & $\begin{array}{l}\text { Percentage of supply costs in relation to total costs per } \\
\text { unit for the SME-supplier }\end{array}$ & $40 \%$ \\
\hline$P_{1}$ & Price of a unit semi-finished goods & 13 \\
\hline$r_{O E M}$ & Cost reduction per unit due to volume discount & Dependent \\
\hline$V_{D}$ & Value saved due to the volume discount & Dependent \\
\hline$H R_{F}$ & Human resource costs due to natural hedging & Dependent \\
\hline$T F_{F}$ & $\begin{array}{l}\text { Hedging fees depending by fixed as well as variable elem- } \\
\text { ents }\end{array}$ & Dependent \\
\hline $\operatorname{VaR}_{\text {res }}$ & Steady residual risk $\operatorname{VaR}_{F}$ which the OEM cannot hedge & Dependent \\
\hline $\operatorname{VaR}_{C R}$ & $\begin{array}{l}\text { Credit risk due to SME-supplier insolvency and/or deteri- } \\
\text { oration }\end{array}$ & Dependent \\
\hline
\end{tabular}




\begin{tabular}{|c|c|c|}
\hline Variable & Explanation & Scenario assumption \\
\hline $\bar{u}$ & $\begin{array}{l}\text { Explains whether an OEM already has a commodity } \\
\text { hedging team in place }\end{array}$ & $\overline{1}$ \\
\hline$l$ & $\begin{array}{l}\text { If the OEM doesn't have a commodity hedging team in } \\
\text { place, this variable describes how much would have to be } \\
\text { invested }\end{array}$ & $300 ’ 000$ \\
\hline$w, \mu$ & $\begin{array}{l}\text { Describe how human resource costs decrease with rising } \\
\text { volumes }\end{array}$ & $-0.35,51.8$ \\
\hline$m$ & $\begin{array}{l}\text { Total amount of commodities purchased by the OEM due } \\
\text { to natural hedging }\end{array}$ & Input to scenario \\
\hline$P_{B}$ & Base human resource cost per unit & 5 \\
\hline$z$ & Describes how often hedging transactions take place & 4 \\
\hline$k f$ & Describes the fixed hedging costs per transaction & 1000 \\
\hline$q$ & Describes which part of the internalized $\operatorname{VaR}_{F}$ cannot be & 0.01 \\
\hline$v$ & $\begin{array}{l}\text { hedged by the OEM } \\
\text { Describes the total value of purchased commodities by the } \\
\text { OEM }\end{array}$ & Dependent \\
\hline$\lambda$ & $\begin{array}{l}\text { Describes the percentage of volume a certain supplier has } \\
\text { in relation to the entire purchasing volume }\end{array}$ & Dependent \\
\hline$\gamma$ & Describes which percentage of the SME-supplier is at risk & 0.3 \\
\hline$\omega$ & Describes the probability of an SME-supplier credit risk & 0.03 \\
\hline$T_{N}$ & $\begin{array}{l}\text { Transport costs from the commodity supplier to the SME- } \\
\text { supplier (SQ) }\end{array}$ & Dependent \\
\hline$T_{\text {OEM } 1}$ & $\begin{array}{l}\text { Transport costs from the commodity supplier to the OEM } \\
\text { (NH) }\end{array}$ & Dependent \\
\hline$T_{O E M}$ & Transport costs from the OEM to the SME-supplier (NH) & Dependent \\
\hline$m$ & $\begin{array}{l}\text { Total amount of commodities purchased by the OEM due } \\
\text { to natural hedging }\end{array}$ & Input to scenario \\
\hline$m_{n}$ & $\begin{array}{l}\text { Total amount of commodities purchased by the SME-sup- } \\
\text { plier }\end{array}$ & Input to scenario \\
\hline$w, \mu$ & Describe how transport costs decrease with rising volumes & $-0.35,51.8$ \\
\hline$P_{B}$ & Base transport cost per unit & 6 \\
\hline$e_{n}$ & Transport cost per unit & Dependent \\
\hline$y$ & Distance from to the OEM & Input to scenario \\
\hline$y_{n}$ & Distances to the SME-supplier & Input to scenario \\
\hline$f$ & Cost per distance $(\mathrm{km})$ & 15 \\
\hline$H R_{n}$ & $\begin{array}{l}\text { Human resource (incl. transaction and coordination costs) } \\
\text { of the SME-supplier (SQ) }\end{array}$ & Dependent \\
\hline$H R_{O E M 1}$ & $\begin{array}{l}\text { Human resource (incl. transaction and coordination costs) } \\
\text { of the OEM (NH) }\end{array}$ & Dependent \\
\hline$H_{\text {OEM }}$ & $\begin{array}{l}\text { Human resource (incl. transaction and coordination costs) } \\
\text { of the SME-supplier (NH) }\end{array}$ & Dependent \\
\hline$m$ & $\begin{array}{l}\text { Total amount of commodities purchased by the OEM due } \\
\text { to natural hedging }\end{array}$ & Dependent \\
\hline$m_{n}$ & $\begin{array}{l}\text { Total amount of commodities purchased by the SME-sup- } \\
\text { plier }\end{array}$ & Dependent \\
\hline$w, \mu$ & $\begin{array}{l}\text { Describe how human resource costs decrease with rising } \\
\text { volumes }\end{array}$ & $-0.35,51.8$ \\
\hline$P_{B}$ & Base human resource costs per unit & $5 ; 3$ \\
\hline$g_{n}$ & Human resource costs per unit & Dependent \\
\hline
\end{tabular}




\begin{tabular}{llr}
\hline Variable & Explanation & Scenario assumption \\
\hline$I_{N}$ & Inventory costs of the SME-supplier (SQ) & Dependent \\
$I_{\text {OEM } 1}$ & Inventory costs of the OEM (NH) & Dependent \\
$I_{O E M}$ & Inventory costs of the SME-supplier (NH) & Dependent \\
$m$ & Total amount of commodities purchased by the OEM due & Input to scenario \\
& to natural hedging & \\
$m_{n}$ & Total amount of commodities purchased by the SME-sup- & Input to scenario \\
$w, \mu$ & plier & $-0.35,51.8$ \\
$P_{B}$ & Describe how transport costs decrease with rising volumes & $20 ; 10$ \\
$h_{n}$ & Base transport cost per unit & Inventory cost per unit \\
$t$ & Inventory duration at the OEM & $25 ; 5$ \\
$t_{n}$ & Inventory duration at the SME-supplier & 60 \\
$j$ & Cost per time unit (day) & 30 \\
\hline
\end{tabular}

Table A1: Assumptions for scenario analysis

\section{References}

Adams, J.B./Montesi, C.J. (1995): Major Issues Related to Hedge Accounting. Financial Accounting Standard Board, Newark, Connecticut.

Allayannis, G., et al. (2001): Exchange-rate hedging: Financial versus operational strategies, in: American Economic Review, Vol. 91, No. 2, pp. 391-395.

Barry, J. (2004): Perspectives: supply chain risk in an uncertain global supply chain environment, in: International Journal of Physical Distribution \& Logistics Management, Vol. 34, No. 9, pp. 695-697.

Caldentey, R./Haugh, M.B. (2006): Optimal control and hedging of operations in the presence of financial markets, in: Mathematics of Operations Research, Vol. 31, No. 2, pp. 285-304.

Caldentey, R./Haugh, M.B. (2009): Supply contracts with financial hedging, in: Operations Research, Vol. 57, No. 1, pp. 47-65.

Cavinato, J.L. (2004): Supply chain logistics risks: from the back room to the board room, in: International Journal of Physical Distribution \& Logistics Management, Vol. 34, No. 5, pp. 383-387.

Chopra, S./Sodhi, M.S. (2004): Managing risk to avoid supply-chain breakdown, in: MIT Sloan Management Review, Vol. 46, No. 1, pp. 53-62.

Choudhry, M. (2006): An Introduction to Value-at-Risk, 4th Ed., New York.

Christopher, M./Lee, H. (2004): Mitigating supply chain risk through improved confidence, in: International Journal of Physical Distribution \& Logistics Management, Vol. 34, No. 5, pp. 388-396.

Cohen, B.J. (2009): Dollar dominance, Euro aspirations: Recipe for discord?, in: Journal of Common Market Studies, Vol. 47, No. 4, pp. 741-766.

Cohen, M.A./Mallik, S. (1997): Global supply chains: Research and applications, in: Production \& Operations Management, Vol. 6, No. 2, pp. 193-210.

Cossin, D./Schellhorn, H. (2007): Credit risk in a network economy, in: Management Science, Vol. 53, No. 10, pp. 1604-1617.

Cucchiella, F./Gastaldi, M. (2006): Risk management in supply chain: a real option approach, in: Journal of Manufacturing Technology Management, Vol. 17, No. 6, pp. 700-720. 
Das, T.K./Teng, B.S. (1998): Resource and risk management in the strategic alliance-making process, in: Journal of Management, Vol. 24, No. 1, pp. 21-42.

Devlin, G. (2004): Wall Street risk tools applied to automotive supply chain, in: MSI Manufacturing Systems, Vol. 22, No. 12, p. 9.

Ding, Q., et al. (2007): On the integration of production and financial hedging decisions in global markets, in: Operations Research, Vol. 55, No. 3, pp. 470-489.

Duangploy, O./Helmi, D. (2000): Foreign currency hedge accounting: multi-currency versus functional currency accounting, in: Managerial Auditing Journal, Vol. 15, No. 3, pp. 232-246.

Gotoh, J./Takano, Y. (2006): Newsvendor solutions via conditional value-at-risk minimization, in: European Journal of Operations Research, Vol. 179, No. 1, pp. 80-96.

Guay, W./Kothari, S.P. (2003): How much do firms hedge with derivatives?, in: Journal of Financial Economics, Vol. 70, No. 3, pp. 423-461.

Harland, C., et al. (2003): Risk in supply networks, in: Journal of Purchasing \& Supply Management, Vol. 9, No. 2, pp. 51-62.

Hendricks, K.B./Singhal, V.R. (2003): The effect of supply chain glitches on shareholder wealth, in: Journal of Operations Management, Vol. 21, No. 5, pp. 501-522.

Hendricks, K.B./Singhal, V.R. (2005): Association between supply chain glitches and operating performance, in: Management Science, Vol. 51, No. 5, pp. 695-711.

Hutchison, P.D., et al. (2009): Supply chain cash-to-cash, in: Strategic Finance, Vol. 91, No. 1, pp. 41-48.

Jacques, L.L. (1981): Management of Foreign Exchange Risk: A Review Article, in: Journal of International Business Studies, Vol. 12, No. 1, pp. 81-101.

Jorion, P. (2002): Value at risk: the new benchmark for managing financial risk, 2nd Ed., Boston.

Jüttner, U., et al. (2003): Supply chain risk management: Outlining an agenda for future research, in: International Journal of Logistics: Research \& Applications, Vol. 6, No. 4, pp. 197-210.

Jüttner, U. (2005): Supply chain risk management: Understanding the business requirements from a practitioner perspective, in: The International Journal of Logistics Management, Vol. 16, No. 1, pp. 120-141.

Khan, O./Burnes, B. (2007): Risk and supply chain management: Creating a research agenda, in: The International Journal of Logistics Management, Vol. 18, No. 2, pp. 197-216.

Kleindorfer, P.R./Saad, G.H. (2005): Managing disruption risks in supply chains, in: Production \& Operations Management, Vol. 14, No. 1, pp. 53-68.

Kuwornu, J.K.M., et al. (2009): Agency problem and hedging in agri-food chains: Model and application, in: Journal of Marketing Channels, Vol. 16, No. 3, pp. 265-289.

Kyte, A. (2002): The hedging imperative: making the choices, in: Balance Sheet, Vol. 10, No. 2, pp. $32-40$.

Lee, H.L. (2002): Aligning supply chain strategies with product uncertainties, in: California Management Review, Vol. 44, No. 3, pp. 105-119.

Makar, S.D., et al. (1999): The management of foreign currency risk: derivatives use and the natural hedge of geographic diversification, in: Accounting \& Business Research, Vol. 29, No. 3, pp. 229-237.

Manuj, I./Mentzer, J.T. (2008 a): Global supply chain risk management strategies, in: International Journal of Physical Distribution \& Logistics Management, Vol. 38, No. 3, pp. 192-223. 
Manuj, I./Mentzer, J.T. (2008 b): Global supply chain risk management, in: Journal of Business Logistics, Vol. 29, No. 1, pp. 133-154.

Mentzer, J.T., et al. (2001): Defining supply chain management, in: Journal of Business Logistics, Vol. 22, No. 2, pp. 1-25.

Meredith, J. (1993): Theory building through conceptual methods, in: International Journal of Operations \& Production Management, Vol. 13, No. 5, pp. 3-11.

Norrman, A./Jansson, U. (2004): Ericsson's proactive supply chain risk management approach after a serious sub-supplier accident, in: International Journal of Physical Distribution \& Logistics Management, Vol. 34, No. 5, pp. 434-456.

Peck, H. (2005): Drivers of supply chain vulnerability: An integrated framework, in: International Journal of Physical Distribution \& Logistics Management, Vol. 35, No. 4, pp. 210-232.

Plambeck, E.L./Taylor, T.A. (2007): Implications of renegotiation for optimal contract flexibility and investment, in: Management Science, Vol. 53, No. 12, pp. 1872-1886.

Sanders, D.R./Manfredo, M.R. (2002): The role of value-at-risk in purchasing: An application to the foodservice industry, in: Journal of Supply Chain Management: A Global Review of Purchasing \& Supply, Vol. 38, No. 2, pp. 46-53.

Schrand, C.M./Unal, H. (1998): Hedging and coordinated risk management: Evidence from thrift conversions, in: Journal of Finance, Vol. 53, No. 3, pp. 979-1013.

Sedgwick, D., et al. (2008): As dollar dives, automakers juggle global strategies, in: Automotive News, Vol. 82, No. 6298, p. 30.

Simons, R. (1999): How risky is your company?, in: Harvard Business Review, Vol. 77, No. 3, pp. 85-94.

Snyder, J./Ostle, D. (2003): For now, Germans are protected from impact of strong Euro, in: Automotive News Europe, Vol. 8, No. 10, p. 1.

Stein, J.C. (1997): Internal capital markets and the competition for corporate resources, in: The Journal of Finance, Vol. 52, No. 1, pp. 111-133.

Takezawa, N., et al. (2007): Risk hedging through forward supply contract and equity ownership in a spin-off decision, in: International Journal of Production Economics, Vol. 106, No. 2, pp. 532-543.

Tang, C.S. (2006): Perspectives in supply chain risk management, in: International Journal of Production Economics, Vol. 103, No. 2, pp. 451-488.

Teague, P. (2009): The irony of higher prices, in: Purchasing, Vol. 138, No. 7, p. 18.

Tella, E./Virolainen, V.-M. (2005): Motives behind purchasing consortia, in: International Journal of Production Economics, Vol. 93/94, pp. 161-168.

Tomlin, B./Wang, Y. (2005): On the value of mix flexibility and dual sourcing in unreliable newsvendor networks, in: Manufacturing \& Service Operations Management, Vol. 7, No. 1, pp. 37-57.

Vaagen, H./Wallace, S.W. (2008): Product variety arising from hedging in the fashion supply chains, in: International Journal of Production Economics, Vol. 114, No. 2, pp. 431-455.

Vermond, K. (2007): Canadian dollar blues?, in: CMA Management, Vol. 81, No. 2, pp. 22-25.

VW Investor Relations (2004): Volkswagen: Konzern detailliert Entwicklung 2003, Wolfsburg.

VW Konzern (2006): Konzernabschluss, Wolfsburg. 
Wacker, J.G. (2008): A conceptual understanding of requirements for theory-building research: Guidelines for scientific theory building, in: Journal of Supply Chain Management: A Global Review of Purchasing \& Supply, Vol. 44, No. 3, pp. 5-15.

Watson, A. (1994): Finance of International Trade, London.

White, D. (1995): Application of system thinking to risk management: a review of the literature, in: Management Decision, Vol. 33, No. 10, pp. 35-45.

Zsidisin, G.A., et al. (2004): An analysis of supply risk assessment techniques, in: International Journal of Physical Distribution \& Logistics Management, Vol. 34, No. 5, pp. 397-413.

Erik Hofmann, Prof. Dr., ist Vize-Direktor am Lehrstuhl für Logistikmanagement (LOGHSG) und Assistenzprofessor an der Universität St. Gallen.

Anschrift: Universität St. Gallen, Lehrstuhl für Logistikmanagement (LOG-HSG), Dufourstrasse $40 \mathrm{a}, 9000$ St. Gallen, Schweiz, Tel.: +41 (0)71/224-72-95, Fax: +41 (0)71/224-73-15, E-Mail: erik.hofmann@unisg.ch 